\title{
Decreased Anxiety, Altered Place Learning, and Increased CA1 Basal Excitatory Synaptic Transmission in Mice with Conditional Ablation of the Neural Cell Adhesion Molecule L1
}

\author{
Janice W. S. Law, ${ }^{1,2}$ Alan Y. W. Lee, ${ }^{1}$ Mu Sun, ${ }^{1}$ Alexander G. Nikonenko, ${ }^{1}$ Sookja K. Chung, ${ }^{2}$ Alexander Dityatev, ${ }^{1}$ \\ Melitta Schachner, ${ }^{1}$ and Fabio Morellini ${ }^{1}$ \\ ${ }^{1}$ Zentrum für Molekulare Neurobiologie, Universität Hamburg, D-20246 Hamburg, Germany, and ${ }^{2}$ Institute of Molecular Biology, The University of Hong \\ Kong, Pokfulam, Hong Kong, China
}

\begin{abstract}
L1, a neural cell adhesion molecule of the immunoglobulin superfamily, is involved in neuronal migration and differentiation and axon outgrowth and guidance. Mutations in the human and mouse L1 gene result in similarly severe neurological abnormalities. To dissociate the functional roles of L1 in the adult brain from developmental abnormalities, we have generated a mutant in which the L1 gene is inactivated by cre-recombinase under the control of the calcium/calmodulin-dependent kinase II promoter. This mutant (LIfy+) did not show the overt morphological and behavioral abnormalities observed previously in constitutive L1-deficient $(L 1-/-)$ mice; however, there was an increase in basal excitatory synaptic transmission that was not apparent in $L 1-/-$ mice. Similar to $L 1-/-$ mice, no defects in short- and long-term potentiation in the CA1 region of the hippocampus were observed. Interestingly, L1fy+ mice showed decreased anxiety in the open field and elevated plus-maze, contrary to $L 1-/-$ mice, and altered place learning in the water maze, similar to $L 1-/-$ mice. Thus, mice conditionally deficient in L1 expression in the adult brain share some abnormalities, but also display different ones, as compared with $L 1-/-$ mice, highlighting the role of $\mathrm{L} 1$ in the regulation of synaptic transmission and behavior in adulthood.
\end{abstract}

Key words: anxiety; cell adhesion molecule; hippocampus; L1; place learning; synaptic plasticity

\section{Introduction}

Recognition molecules are implicated not only in cell interactions during nervous system development, but they are also recognized as important mediators of synaptic plasticity in the adult (Schachner, 1997; Murase and Schuman, 1999; Benson et al., 2000). Among these molecules are the cadherins (Fannon and Colman, 1996; Tang et al., 1998), integrins (Staubli et al., 1998) and members of the immunoglobulin superfamily, such as the neural cell adhesion molecule N-CAM (Lüthi et al., 1994; Dityatev et al., 2000) and its associated $\alpha-2,8$ polysialic acid (Muller et al., 1996; Eckhardt et al., 2000), F3/F11/contactin (Perrin et al., 2001), and L1 (Lüthi et al., 1994).

L1 was discovered as a transmembrane glycoprotein in the mouse (Lindner et al., 1983; Rathjen and Schachner, 1984), subserving neuron-neuron adhesion via homophilic and hetero-

Received March 17, 2003; revised Sept. 3, 2002; accepted Sept. 5, 2003.

This work was supported by the Volkswagenstiftung, the Deutsche Forschungsgemeinschaft (SCHA185/32-1), the European community (QLKG-CT-1999-02187) (M.S.), the Deutscher Akademischer Austauschdienst (M.S.), and the Alexander von Humboldt Foundation (A.Y.W.L.). We thank Drs. Michael Bösl for help in the transgenic mouse facility, Günther Schütz for the $\alpha$ CaMKII-cre transgenic mice, Francis Stewart for the plasmid pFLPe, Gail Martin for the pgk-neomycin resistance cassette, and Andreas Nagy for embryonic stem cells.

Correspondence should be addressed to Fabio Morellini, Zentrum für Molekulare Neurobiologie, Universität Hamburg, Martinistrasse 52, 20246 Hamburg, Germany. E-mail: fmorell@zmnh.uni-hamburg.de.

A. Y. W. Lee's present address: Department of Physiology, National University of Singapore, 2 Medical Drive, S117597 Singapore.

Copyright $\odot 2003$ Society for Neuroscience 0270-6474/03/2310419-14\$15.00/0 philic interactions with other adhesion and extracellular matrix molecules. It promotes neurite outgrowth and fasciculation (Fischer et al., 1986), axon pathfinding (Cohen et al., 1998), cerebellar granule cell migration (Lindner et al., 1983), and myelination (Wood et al., 1990). Mutants constitutively deficient in L1 $(L 1-/-)$ show severe abnormalities in the development of the central and peripheral nervous systems (Dahme et al., 1997; Cohen et al., 1998), which lead to an altered behavioral phenotype. In humans, mutations in the $\mathrm{L} 1$ gene result in mental retardation, aphasia, shuffling gate, and adducted thumbs (MASA syndrome), hydrocephalus as a result of stenosis of the aqueduct of Sylvius (HSAS syndrome), spastic paraplegia type 1B, and agenesis of the corpus callosum (for review, see Kenwrick et al., 2000).

Because behavioral alterations of $L 1-/-$ mutants could result from abnormal development, it seemed necessary to dissociate the functions of L1 during development from those in the adult. We therefore have generated a mutant in which L1 is ablated by inactivation of the L1 gene after cessation of the major developmental events by crossing a mouse mutant carrying loxP sites in the L1 gene with a transgenic mouse that expresses the crerecombinase under the control of the calcium-dependent calmodulin kinase II ( $\alpha$ CaMKII) promoter (Mayford et al., 1995; Mantamadiotis et al., 2002). This conditional mutant (L1fy+) with ablation of L1 in the adult brain does not show any of the abnormalities in gross morphology described for the $L 1-/-$ mu- 
tant. In contrast to $L 1-/-$ mice, $L 1 f y+$ mice reveal an increase in basal excitatory synaptic transmission, whereas long-term potentiation (LTP) in the CA1 region of the hippocampus is normal in both mutants. L1fy + mice are less anxious in the open field and elevated plus-maze, and they are altered in place learning in the water maze, suggesting that L1 plays important functional roles in the adult brain, independent of development.

\section{Materials and Methods}

\section{Antibodies}

Polyclonal antibodies against mouse L1 have been described (Dahme et al., 1997). Monoclonal antibody against glyceraldehyde-3-phosphate dehydrogenase (GAPDH) was from Chemicon (Temecula, CA). Polyclonal antibodies against parvalbumin were from Sigma-Aldrich (Deisenhofen, Germany). Polyclonal antibodies against neurofilament were from Serotec (Duesseldorf, Germany). Polyclonal antibodies against glial fibrillary acidic protein (GFAP) were from Roche Diagnostics (Mannheim, Germany). Horseradish peroxidase-conjugated secondary antibodies against the respective primary antibodies were from Dianova (Hamburg, Germany), and biotinylated secondary antibodies were from Vector Laboratories (Grünberg, Germany).

\section{Construction of targeting vector}

A cDNA probe harboring exons 4 and 5 of mouse L1 was used to screen a $129 / \mathrm{SvJ}$ mouse $\lambda$ phage genomic library (Stratagene, Amsterdam, The Netherlands), resulting in the isolation of a clone that contains exons 2-26 of the murine L1 gene. To facilitate subsequent construction of the L1 gene targeting vector, a $8.5 \mathrm{~kb}$ XhoI fragment spanning exons 3-13 was shuttled from this genomic phagemid to a plasmid vector. The target exon 5 was then excised from the resulting plasmid and subcloned into the BamHI site of a pBS2loxP vector in such a way that it was flanked by two loxP sequences (so-called "floxed") oriented in the same direction. The pgk-neomycin-resistance (neo) cassette, flanked by a pair of frt sequences (so-called "flrted") (kindly provided by Dr. Gail Martin, University of California, San Francisco, CA) was then inserted downstream of exon 5, resulting in a loxP-exon5-frt-neo-frt-loxP sandwich (see Fig. $1 A$ ). The targeting vector was subsequently completed by a $1.7 \mathrm{~kb}$ homology arm (left) upstream of the first loxP site and a $3.3 \mathrm{~kb}$ arm (right) $3^{\prime}$ to the last loxP.

\section{Generation of L1-floxed and conditional L1-deficient mice}

R1 embryonic stem (ES) cells $\left(1 \times 10^{7}\right)$ (kindly provided by Dr. Andreas Nagy, Samuel Lunenfeld Research Institute, Toronto, Canada) were electroporated with $30 \mu \mathrm{g}$ of the linearized targeting vector at $3 \mu \mathrm{F}, 800 \mathrm{~V}$, followed by a second pulse of $500 \mu \mathrm{F}, 250 \mathrm{~V}$. The cells were then subjected to geneticin (G418) selection at $250 \mu \mathrm{g} / \mathrm{ml}$ for $7 \mathrm{~d}$. Surviving clones were isolated, expanded, and screened for the occurrence of homologous recombination events by Southern blot analysis of SacI-digested genomic DNA using the $5^{\prime}$ probe depicted in Figure $1 A$. Targeted ES cell clones were then transiently transfected with a Flp-recombinase expression plasmid pFLPe (kindly provided by Dr. Francis Stewart, European Molecular Biology Laboratory, Heidelberg, Germany) to remove the flrted neomycin cassette. After confirming this removal by Southern blot analysis, positive clones were injected into $\mathrm{C} 57 \mathrm{BL} / 6 \mathrm{~J}$ blastocysts to generate chimeric mice that carry the L1-floxed allele. Chimeric founders were crossed with C57BL/6J mice for three generations before being bred to homozygosity. To generate conditional L1-deficient mice, homozygous L1-floxed females were crossed with transgenic males (on the C57BL/6J genotype background) that express cre-recombinase under the control of the calcium/calmodulin-dependent kinase II $\alpha$ subunit of the CaMKII promoter (kindly provided by Dr. Günther Schütz, German Cancer Research Center, Heidelberg, Germany). This transgenic line (CaMKII4) has been described recently by Mantamadiotis and colleagues (2002), who showed cre-recombinase expression in striatum, nucleus accumbens, thalamus, amygdala, cortex, and hippocampus. All resulting male progeny were homozygous for the L1-floxed allele, among which $50 \%$ carried the $\alpha$ CaMKII-cre transgene (designated L1fy + ) and 50\% did not (designated L1fy-). These mice have a mixed 129/Sv and C57BL/6J genetic background (four backcrossings into the C57BL/6J strain). Unless stated otherwise, all experiments in the present study were performed on male mice.

\section{Southern blot and PCR analyses}

Genomic DNA was isolated from ES cells or mouse tail biopsies by phenol-chloroform extraction. DNA $(20 \mu \mathrm{g})$ was digested with appropriate restriction enzymes, fractionated on $0.7 \%$ agarose gel, and transferred onto nylon membrane (Hybond $\mathrm{N}+$, Amersham Biosciences, Braunschweig, Germany). Hybridization was performed at $65^{\circ} \mathrm{C}$ in hybridization buffer using ${ }^{32} \mathrm{P}$-labeled cDNA fragments as probes $\left(5^{\prime}\right.$ and $3^{\prime}$ probe in Fig. $1 A$ ). Membranes were subjected to stringency washes in $2 \times, 1 \times$, and $0.1 \times$ SSC buffer. Hybridization signals were detected by $\mathrm{x}$-ray autoradiography.

\section{Western blot analysis}

Whole-brain or isolated brain regions (hippocampus and cerebellum) of different ages were homogenized in ice-cold lysis buffer containing 20 mм Tris- $\mathrm{HCl}, \mathrm{pH}$ 8.0, 1\% NP-40, $150 \mathrm{~mm} \mathrm{NaCl}, 1$ mм EDTA, 1 mм sodium orthovanadate, and protease inhibitor mixture (Roche Biochemicals). Crude protein extract was obtained by clearing the lysate by centrifugation. Aliquots of the proteins were subjected to SDS-PAGE and transferred onto nitrocellulose filters (Protran; Schleicher \& Schuell, Dassel, Germany). Membranes were pretreated with $2 \%$ nonfat dry milk and $0.1 \%$ Tween 20 in PBS, pH 7.3, followed by incubation with L1 polyclonal antibodies (1:5000). After washing in PBS, the blots were incubated with horseradish peroxidase-conjugated anti-rabbit secondary antibodies (1:5000). Immunoreactivity was detected by enhanced chemiluminescene (ECL kit, Amersham Biosciences) on x-ray film (Kodak Biomax) according to the manufacturer's instructions. Band intensity was quantified with densitometry.

\section{Histological and immunohistochemical analyses}

Mice were anesthetized and perfused transcardially with 4\% paraformaldehyde in PBS. Brains were isolated and postfixed overnight in the same fixative. For Nissl staining, brains were paraffin embedded, and $5 \mu \mathrm{m}$ sagittal sections were prepared. For immunohistochemical staining, 50 $\mu \mathrm{m}$ vibratome sections were prepared (with the exception of the immunostaining for $\mathrm{L} 1$, for which $40 \mu \mathrm{m}$ sections were used). Sections were incubated in $1 \%$ potassium borohydride in PBS for $10 \mathrm{~min}$, followed by an ascending series of ethanol. They were then blocked with $10 \%$ horse serum and $0.1 \%$ bovine serum albumin (BSA) in PBS. Polyclonal antibodies against parvalbumin (1:1000), neurofilament (1:1000), GFAP (1: 1000 ) in PBS with $1 \%$ horse serum, and $0.1 \%$ BSA were used. Immunoreactivities were detected using the appropriate biotinylated secondary antibodies (1:1000) and the ABC Elite Kit from Vector Laboratories. Nickel-enhanced $0.03 \%$ diaminobenzidine $/ 0.015 \% \mathrm{H}_{2} \mathrm{O}_{2}$ was used as chromogen. L1 immunostaining was analyzed in three L1fy+ mice and two L1fy-littermates at the age of 5 months. As control for specificity, two L1-/y male mice were used. Brain tissue was prepared as described above. Affinity-purified polyclonal rabbit antibodies against L1 (1:100 in PBS with $0.1 \%$ BSA) were used to analyze L1 expression in $40-\mu \mathrm{m}$-thick vibratome slices taken from different regions of the brains of mutant and wild-type mice. Immunoreactivity was detected using Cy3-conjugated goat anti-rabbit antibodies (Jackson ImmunoResearch Laboratories, purchased from Dianova, Hamburg, Germany) at a dilution of 1:200. All sections were examined with an Axiophot microscope (Carl Zeiss, Göttingen, Germany).

\section{Morphological analysis}

To investigate the general morphology of the brain, five 3-month-old $L 1 f y+$ mice and five L1fy-littermates were deeply anesthetized with chloralhydrate and perfused transcardially with a mixture of $2 \%$ formaldehyde and $2.5 \%$ glutaraldehyde in $0.1 \mathrm{~m}$ phosphate buffer, $\mathrm{pH}$ 7.4. After perfusion, brains were removed, weighed, and kept overnight at $4^{\circ} \mathrm{C}$ in $4 \%$ formaldehyde and 5\% glutaraldehyde in the same buffer. Cerebella were then separated from brains, embedded in agar, and cut sagittally with a Vibratome (Leica, Wetzlar, Germany) in 200- $\mu$ m-thick slices. The same approach was used to prepare $200-\mu \mathrm{m}$-thick coronal slices of the brains. Tissue slices were postfixed for $1.5 \mathrm{hr}$ in $0.1 \mathrm{M}$ cacodylate buffer containing $1 \% \mathrm{OsO}_{4}$. Slices were then dehydrated and flat embedded in 
Epon resin. The general morphology of different brain areas was analyzed in semithin, $1-\mu \mathrm{m}$-thick sections stained with a mixture of $1 \%$ methylene blue and $1 \%$ toluidine blue. Cross-sectional areas of the brain, cerebellar vermis, and granular layer of the cerebellum were measured with the free UTHSCSA ImageTool program (University of Texas, San Antonio, TX) in digitized micrographs of unstained vibratome sections taken at a magnification of $5000 \times$ with an Axiophot 2 microscope equipped with an AxioCam HRc digital camera. To evaluate the crosssectional area of the brain and of the lateral ventricles, four coronal brain sections from five mice per genotype comparable with section 44 of Franklin and Paxinos (1997) were measured, and values were averaged per mouse. To estimate the cross-sectional area of the cerebellar vermis and granular layer of the cerebellum, four parasagittal cerebellar sections closest to the sagittal plane were analyzed, and values were averaged per mouse. Final values are expressed in square millimeters.

\section{Behavioral analysis}

Animals. Twelve- to 15-week-old males (12 L1fy- mice and 12 Llfy + littermates) were transferred from the breeding facility into an animal room with a new $12 \mathrm{hr}$ light/dark cycle (lights on at 7:00 A.M.) and maintained in groups of three to four (at least one mouse from each genotype in each group) under standard housing conditions $\left(21 \pm 1^{\circ} \mathrm{C}\right.$; $50 \%$ humidity; food and water ad libitum). After 2 weeks, mice were tested in the open field and, $72 \mathrm{hr}$ later, in the elevated plus-maze. Mice were then single-housed for $10 \mathrm{~d}$ before being tested in experiment 1 of the water-maze task. A new batch of 10 L1fy-male mice and 10 Llfy+ male littermates were used for experiments 2 and 3 of the water-maze task. These mice were housed singly $10 \mathrm{~d}$ before being trained in the water maze. All behavioral tests were performed starting $2 \mathrm{hr}$ after light offset and finishing at least $2 \mathrm{hr}$ before light onset. Behavior was video recorded and analyzed off-line. The experimental room, adjacent to the animal room, was illuminated by dim red light.

Open field. The open field consisted of a wooden box $(50 \times 50 \times 40$ $\mathrm{cm}$ ) laminated with rough, matted, light-gray resin and illuminated by a white bulb (50 Lux). Each mouse was gently introduced into a cylinder of opaque Plexiglas placed at one corner of the box for $\sim 5 \mathrm{sec}$. As the cylinder was lifted, the mouse could move freely in the arena for a duration of $15 \mathrm{~min}$. Distance moved, mean velocity, mean distance to the wall, and time spent in the center (an imaginary inner square of $20 \times 20 \mathrm{~cm}$ ) were analyzed with the software EthoVision (Noldus, Wageningen, The Netherlands). The behavior of the mice during the first 5 min of the test was scored using the ethological software The Observer (Noldus) by a trained observer blind to the genotype of the mice. The following behavioral parameters were analyzed: stretch attend posture (the mouse stretches forward and retracts to its original position without forward locomotion), rearing off wall (the mouse stands on its hind limbs), rearing on wall (as rearing on wall but with one of the forepaws touching the wall), and self-grooming.

Elevated plus-maze. The apparatus, made of white plastic, consisted of two opposing open arms $(30 \times 5 \mathrm{~cm})$ and two opposing closed arms (same size of the open arms but with 15-cm-high walls) extending from a central square platform $(5 \times 5 \mathrm{~cm})$. Small rims of $2 \mathrm{~mm}$ at the edge of the open arms provided some gripping surface. The apparatus was elevated $75 \mathrm{~cm}$ above the floor and illuminated with dim white light (2 Lux). Animals were placed in the center of the maze facing one open arm and returned to their home cage after $5 \mathrm{~min}$. The following parameters were analyzed with the software The Observer: number of entries with all the four paws into the arms, time spent on the arms, and risk assessment of the open arms from the protected area (the mouse, standing in the center and closed arms, directs its nose toward one of the open arms).

Water maze: experiment 1 . Mice were trained in a $155-\mathrm{cm}$-diameter circular pool (water at $21 \pm 1^{\circ} \mathrm{C}$, made opaque by a nontoxic white paint; 14-cm-diameter platform placed $1 \mathrm{~cm}$ below the water surface, the center of the platform at $40 \mathrm{~cm}$ from the wall; white wall $20 \mathrm{~cm}$ above the water surface; maximal trial duration $90 \mathrm{sec}$ ) as described previously (Evers et al., 2002). The pool was placed in the center of the experimental room $(3.5 \times 3.5 \mathrm{~m})$, which was provided with six landmarks of the size of $\sim 50 \times 50 \mathrm{~cm}$ placed on the walls at a height of $150-180 \mathrm{~cm}$ as shown in Figure $8 \mathrm{~B}$. Walls, doors, and ceiling of the experimental room were white (painted or covered with cloth) to minimize uncontrolled visual cues. Mice were started from six symmetrical positions in a pseudorandomized order. After staying on the platform for $15 \mathrm{sec}$, mice were returned to their home cage in a room adjacent to the experimental room and kept warm under red light.

Mice were first trained with a cued platform (days 1 and 2; four trials per day; intertrial interval of $1 \mathrm{hr}$ ) so that they could associate the platform with the escape from the pool. The pool was surrounded by a black curtain to occlude the sight of extra-maze cues. The platform was cued by a 15-cm-high dark cylinder placed onto it and located pseudorandomly in different locations across trials. For the spatial learning protocol, all mice were trained over $5 \mathrm{~d}$ (days 3-7; six trials per day, except on day 6 when four trials were performed; intertrial interval of $50 \mathrm{~min}$ ). The platform was hidden and located in the center of quadrant northeast (NE), and the curtain was removed to reveal the extra-maze cues. On the third trial on day 7, the platform was removed, and mice were allowed to swim for $60 \mathrm{sec}$ (transfer trial). For relearning (days 8-11), the hidden platform was placed at the center of quadrant southeast (SE). A platform with a diameter of $5 \mathrm{~cm}$ was used on day 11 with the intent to give an advantage to mice that were able to precisely locate the platform versus mice that found the platform by searching in a broader area. A transfer trial was performed $72 \mathrm{hr}$ after the last trial of day 11 . All trials were analyzed with the video tracking system EthoVision.

Water maze: experiment 2. Several studies showed that rats can form a cognitive map by using the shape of the environment (Cheng, 1986; Ramos, 2000; Pearce et al., 2001), and the geometry of the environment is particularly important in determining place-field location (O'Keefe and Burgess, 1996). Experiment 2 was performed with a strengthened asymmetric shape of the experimental room, to possibly facilitate the formation of a cognitive map. The shape of the room was changed slightly as compared with experiment 1 (see Fig. 9B). Because all of the walls of the room were white, it was possible that mice, known to have a relatively poor visual perception, could not detect the different corners and walls and therefore missed information about the shape of the room. The geometry of the experimental room therefore was strengthened by placing five, vertical, 40-cm-large black stripes in the five corners, going from the ceiling to the floor (see Fig. 9B). Four landmarks were located on the walls at a height of $150-180 \mathrm{~cm}$. Training with a cued platform (day 1-2) and hidden platform (day 3-12) was performed as described for experiment 1 , except for the following changes. Starting from day 7, a $60 \mathrm{sec}$ transfer trial was performed every day after the second training trial, followed by four additional trials. From day 8 onward, some components of the room were removed. On days 8 and 9 , the stripes in the corners were absent, whereas landmarks remained in the same position; on days 10 and 11, the stripes were placed again in the corners, whereas landmarks were absent; on day 12, landmarks and stripes were present again. A transfer trial was performed on day 17, $5 \mathrm{~d}$ after the last training day, with landmarks and stripes present.

Water maze: experiment 3. Chamizo (2002) reported that a landmark differently influences the performance of rats, depending on its relative distance to the goal. We therefore tested whether the performance of $L 1 f y+$ mice could be affected by the landmark position. Two weeks after completing experiment 2 , mice were trained again. The pool was surrounded by a black circular curtain, and two landmarks were placed in positions NE and SW. Mice were first trained (six trials per day; intertrial interval of $50 \mathrm{~min}$ ) to find the hidden platform in the center of quadrant SE equally distant from both landmarks (days 31-32) and then with the hidden platform placed in the center of quadrant southwest (SW) near the landmark in SW (days 33-34) (see Fig. 9D). A transfer trial was performed at the end of training on days 32 and 34 .

\section{Electrophysiological analysis}

Transverse slices of hippocampi were prepared from 8- to 10-week-old L1fy + mice and L1fy- littermates at a thickness of $350 \mu \mathrm{m}$ as described previously (Eckhardt et al., 2000; Saghatelyan et al., 2000). Briefly, anesthetized mice were decapitated, and their brains were removed into icecold artificial CSF (ACSF) containing (in $\mathrm{mM}$ ): 250 sucrose, $25 \mathrm{NaHCO}_{3}$, 25 glucose, $2.5 \mathrm{KCl}, 1.25 \mathrm{NaH}_{2} \mathrm{PO}_{4}, 2 \mathrm{CaCl}_{2}, 1 \mathrm{MgCl}_{2}, \mathrm{pH}$ 7.3. Hippocampal slices were prepared with a Leica VT 1000M Vibratome (Leica, 
Nussloch, Germany) in ice-cold ACSF. The slices were kept at room temperature in carbogen-bubbled ACSF, containing $125 \mathrm{~mm}$ $\mathrm{NaCl}$ instead of $250 \mathrm{~mm}$ sucrose, for at least $2 \mathrm{hr}$ before the start of recordings. Field EPSPs (fEPSPs) in the stratum radiatum of the CA1 region of hippocampus were recorded by using glass pipettes filled with ACSF, with a resistance of 2 $M \Omega$. Two independent pathways were stimulated by a tripolar electrode made from three Teflon-insulated platinum wires (World Precision Instruments, Berlin, Germany). Theta burst stimulation (TBS) (four trains of 10 bursts of four stimuli; $20 \mathrm{sec}, 200 \mathrm{msec}$, and 10 msec intervals between trains, burst, and stimuli, respectively) (Eckhardt et al., 2000) was applied to one of these pathways. The second pathway was used as a control for the stability of recordings. A paired-pulse test was used to control independence of the two pathways. To measure polyspike activity in the CA1 region, the Schaffer collaterals were stimulated by a bipolar platinum electrode placed in the stratum radiatum at a position $\sim 400 \mu \mathrm{m}$ from the recording electrode. The recording glass electrode filled with ACSF, having a resistance of $2 \mathrm{M} \Omega$, was placed in the stratum pyramidale. The duration of stimulation pulses was $0.2 \mathrm{msec}$, and stimulation strength was set to produce population spikes of the maximal amplitude. Afferent stimulation of the Schaffer collaterals at 1 $\mathrm{Hz}$ for $20 \mathrm{sec}$ was used to induce polyspike activity (Lüthi et al., 1997). Data acquisition and analysis were performed using AxoClamp 2B (Axon Instruments, Union City, CA) and PULSE software (HEKA, Lambrecht, Germany).

\section{Statistical analysis}

All data are presented as mean \pm SEM, in addition to morphological data, which are presented as mean \pm SD. Morphological and behavioral data were analyzed with the nonparametric test Mann-Whitney $U$ test. For multifactorial analysis of paired values obtained at different time points or in different quadrants or areas within subjects (different time intervals for the open field test; different trials, days, time intervals, and quadrants/areas for the acquisition phases and transfer trials of the water-maze test), an ANOVA for repeated measures was performed (having genotype as between groups factor), followed by post hoc analysis (Newman-Keuls) when appropriate. Because the three $5 \mathrm{~min}$ intervals of the open field test were arbitrarily generated, values calculated for the total 15 min duration of the test were also analyzed with the Mann-Whitney $U$ test. For brevity, the results of this analysis are presented only if in discordance with the results obtained from the ANOVA for repeated measures. The mean of two consecutive trials was used for graphical representation and statistical analysis of data from the acquisition phases of the water-maze experiments. Data from the electrophysiological study were analyzed with the unpaired $t$ test. All statistical tests were two-tailed.

\section{Results}

\section{Generation of L1-floxed mice}

To restrict ablation of the $\mathrm{L} 1$ gene to brain subregions after early development, we generated a conditional mutant using the bipartite cre-loxP recombination system (Gu et al., 1994). Two genetically modified mice were involved: (1) a chimeric mouse that was engineered in such a way that the target exon of the L1 gene was flanked by a pair of cre-recombinase target sequences called loxP (the L1-floxed mouse), and (2) a transgenic mouse that shows restricted expression of cre-recombinase in the postnatal brain, as regulated by the $\alpha$ CaMKII promoter. To generate the L1-floxed mouse, exon 5 was chosen as the target exon because its removal would lead to a shift in reading frame and termination of translation. The targeting vector was built by inserting a flrted neo cassette at a position downstream of exon 5, which was flanked by a pair of loxP sequences (Fig. $1 A$ ). To screen for ES cells that had undergone homologous recombination with the targeting vector, genomic DNA isolated from clones that had survived G418 selection was digested with SacI and subjected to Southern blot analysis using a $5^{\prime}$ probe as depicted in Figure $1 \mathrm{~A}$. An $8 \mathrm{~kb}$ band was detected for the wild-type L1 allele, whereas a 5 $\mathrm{kb}$ band was observed for the targeted allele because of the introduction of an extra SacI site in the targeting construct (Fig. 1B). Targeted ES cells were then transiently transfected with a Flprecombinase expression vector to remove the flrted neo cassette, 
which may impose undesirable effects on endogenous L1 expression before cre-mediated excision (Jacks et al., 1994; Minichiello et al., 1999). Clones that were free of the neo cassette were distinguished by a $7 \mathrm{~kb}$ band after Southern blot hybridization of HindIII-digested genomic DNA using a $3^{\prime}$ probe (Fig. $1 C$ ). Two independent positive ES cell clones were expanded and microinjected into mouse blastocysts to generate chimeric mice. Germline transmission of the floxed allele was confirmed by Southern blot analysis of HindIII-digested genomic DNA isolated from the resulting progenies (data not shown). To ascertain normal expression of $\mathrm{L} 1$ in the presence of frt and loxP sequences, brains were isolated from L1-floxed mice and their wild-type littermates for Western blot analysis. Both the isoform profile and expression level of L1 in these two genotypes were indistinguishable between the two genotypes, as shown by the similar intensities of the 140 and $200 \mathrm{kDa}$ L1-immunoreactive bands (Fig. 1D).

\section{Generation of conditional L1-deficient mice}

To inactivate L1 in the postnatal brain, L1-floxed mice were crossed with a transgenic mouse line that expresses crerecombinase under the control of $\alpha$ CaMKII promoter. Because of the localization of the L1 gene on the X chromosome, L1floxed males that carry the $\alpha$ CaMKII-cre transgene $(L 1 f y+)$ are expected to display L1 inactivation, whereas L1-floxed males negative for the cre-transgene (L1fy-) are not. Specificity and efficiency of cre-mediated L1 disruption were assayed by Western blot analysis of homogenates isolated from the hippocampus and cerebellum of $L 1 f y+$ and $L 1 f y$ - mice using L1 polyclonal antibodies. At postnatal day (P) 7, there was no difference between the two genotypes in L1 expression in hippocampus and cerebellum (Fig. 2A, top panel), whereas there was a clear reduction in L1 levels in the hippocampus, but not in the cerebellum, at P49 (Fig. $2 \mathrm{~B}$, bottom panel). A significant reduction of $\mathrm{L} 1$ expression was observed at P22 in the hippocampus of L1fy + mice but not in L1fy- littermates (Fig. $2 B$ ). A further reduction of L1 expression to undetectable levels was found in the hippocampus of L1fy+ mice at P49 and P126 (Fig. 2 B). We have not observed L1 immunoreactivity that may represent truncated L1 protein fragments, indicating a complete inactivation of the L1 gene in the hippocampus of $L 1 f y+$ mutants.

To estimate the efficiency of cre-mediated inactivation of L1 expression, $50 \mu \mathrm{g}$ of protein isolated from the hippocampus of $L 1 f y+$ mice and a range of $0.7-50 \mu \mathrm{g}$ of protein from the hippocampus of $L 1 f y$ - littermates at the age of P49 were subjected to Western blot analysis using polyclonal L1 antibodies. Although $\mathrm{L} 1 \mathrm{imm}$ unoreactivity was detectable down to $0.7 \mu \mathrm{g}$ of protein in lysates from $L 1 f y$ - mice, no signal was observed in $50 \mu \mathrm{g}$ of proteins from lysates of L1fy + mice (Fig. 2C). Residual levels of L1 protein in the hippocampus of L1fy + mice thus should not exceed $1.5 \%$ of that in L1fy- littermates.

L1 levels were examined immunohistochemically in 6-month-old mice using constitutive $L 1-/ y$ male mice as a control for the specificity of immunostainings. Coronal sections of the whole brain stained with two different polyclonal antibodies directed against $\mathrm{L} 1$ showed a strong reduction in the amount of $\mathrm{L} 1$ immunoreactivity in the hippocampus, cerebral cortex, and striatum and to a lesser extent in the thalamus and hypothalamus (Fig. $3 A-I$ ) of $L 1 f y+$ mice as compared with those of $L 1 f y$ - littermates, whereas L1 immunoreactivity was unchanged in the molecular layer of the cerebellum (Fig. $3 K, L$ ). As expected, no L1 immunoreactivity was observed in any brain region of $L 1-/ y$ mice (data not shown).

L1fy + mice are normal in body weight and gross behavior and
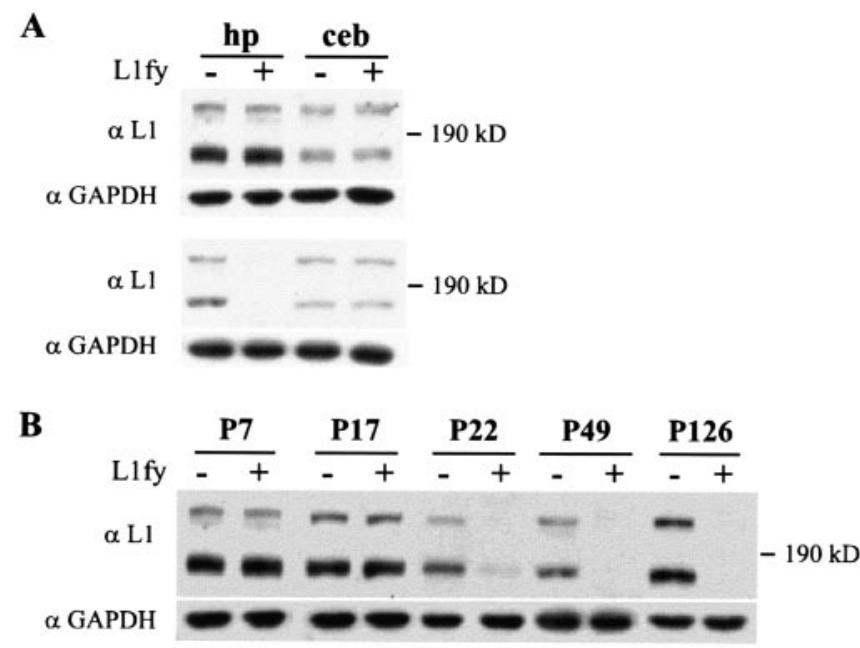

C

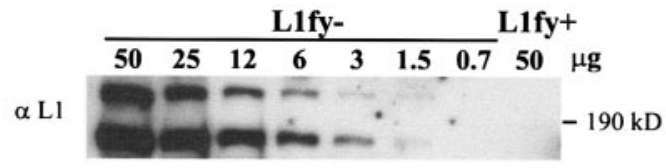

Figure 2. Western blot analysis of $\mathrm{L} 1$ expression in the hippocampus and cerebellum. $A$, Tissue homogenates were prepared from the hippocampus (hp) and cerebellum (ceb) of $L 1 f y$ and L1fy + mice (indicated as - and + , respectively) at P7 and P49. In each lane, $30 \mu \mathrm{g}$ of total protein was loaded and probed with polyclonal L1 antibodies. At P7 (top panel), both the 140 and $200 \mathrm{kDa}$ L1-immunoreactive bands were detectable in the brain regions analyzed, and no genotype difference in expression levels was observed. At P49 (bottom panel), no L1 immunoreactivity was detectable in the hippocampus of $L 7 f y+$ mice, whereas L1 expression was unchanged in the cerebellum. Monoclonal antibodies against GAPDH were used to control for equal protein loading. $B$, Hippocampus homogenates of mice at P7, P17, P22, and P126 were assayed by Western blot analysis as described in A. At P126, analysis was performed in a separate experiment with a prolonged signal exposure time to allow detection of potential L1 expression in L1fy + mice. C, Hippocampus crude lysates isolated from 49-d-old L1fy + mice. Fifty micrograms of hippocampus crude lysates isolated from L7fy $+(50 \mu \mathrm{g}$ of protein) and L1fy(0.7-50 $\mu \mathrm{g}$ of protein) mice were subjected to Western blot analysis to estimate the efficiency of $\alpha$ CaMKII-cre-mediated inactivation of L1 expression in the hippocampus. All samples were pooled from two to three animals.

reproduce according to Mendelian ratios. L1fy + mice have normal fur and normal hindpaw toenail length in contrast to the abnormalities found by Cohen et al. (1998) in the L1-/mutant. Neither sunken and lacrimating eyes nor abnormal head posture, as reported for $L 1-/-$ mutants by Dahme et al. (1997), was observed in L1fy + mice.

\section{Morphological analysis}

Previous studies on $L 1-/-$ mutants revealed several morphological abnormalities in their brains (Dahme et al., 1997; Cohen et al., 1998; Fransen et al., 1998). L1fy + mice were therefore investigated for morphological abnormalities. In 3-month-old L1fy+ mice $(N=5)$, we did not observe enlarged ventricles (Fig. $4 A, B$ ), hydrocephalus, abnormal appearance of the corticospinal tract (Fig. $4 C, D$ ), or vermis hypoplasia (Fig. $4 E, F$ ) as reported for L1-/ - mice. No difference between genotypes was observed in the cross-sectional area of the total brain (L1fy-: $51.2 \pm 1.9 \mathrm{~mm}^{2}$; L1fy $+: 49.9 \pm 2.1 \mathrm{~mm}^{2}$ ), lateral ventricles (L1fy-: $0.48 \pm 0.17$ $\mathrm{mm}^{2}$; L1fy-: $0.52 \pm 0.27 \mathrm{~mm}^{2}$ ), cerebellar vermis (L1fy-: $8.63 \pm$ $0.86 \mathrm{~mm}^{2}$; L1fy+: $8.35 \pm 0.95 \mathrm{~mm}^{2}$ ), or granular layer of the cerebellum (L1fy-: $2.74 \pm 0.3 \mathrm{~mm}^{2} ;$ L1fy+: $2.67 \pm 0.37 \mathrm{~mm}^{2}$ ). Furthermore, no difference was observed in the cross-sectional area of the corticospinal tract of L1fy + mice as compared with 

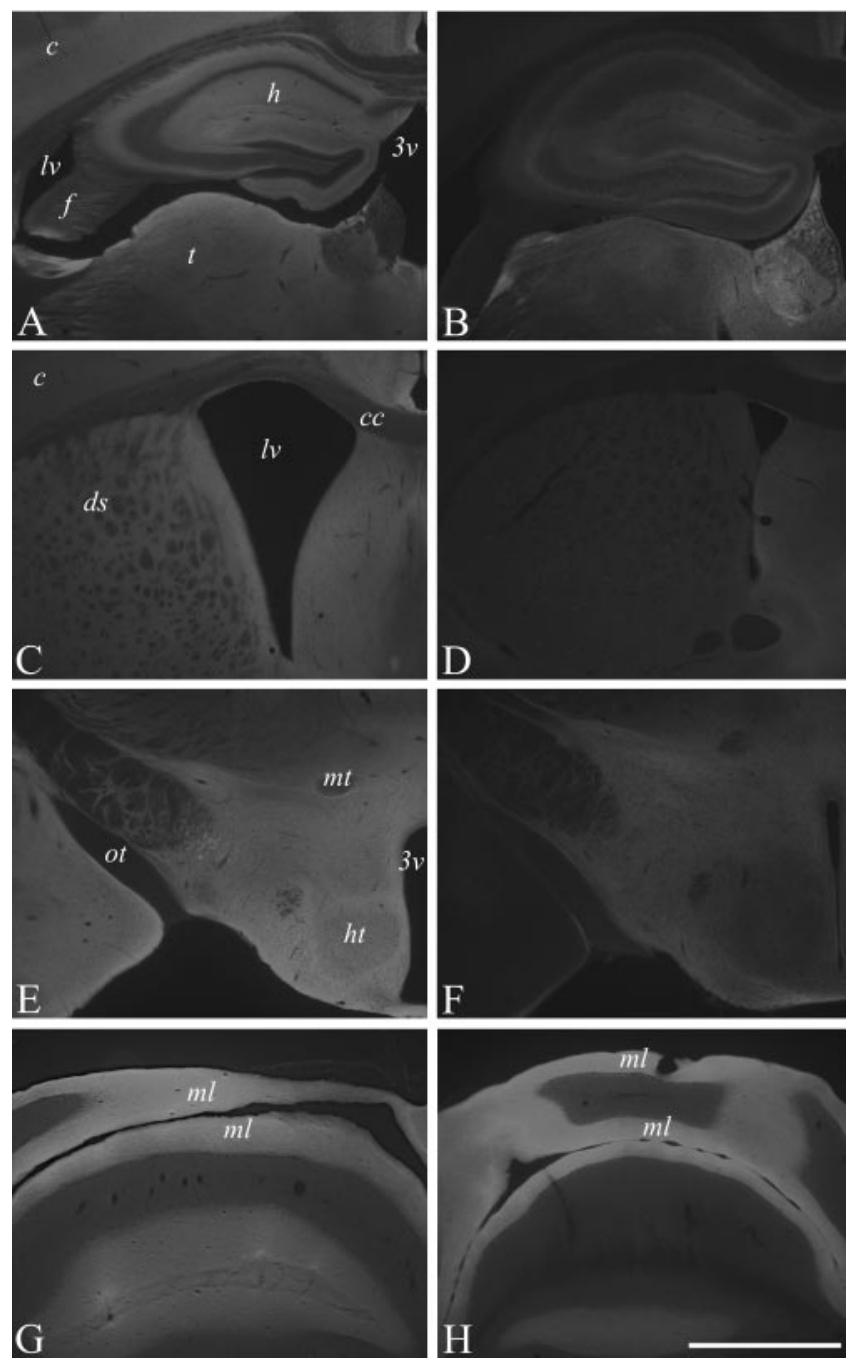

Figure 3. Decreased L1 immunoreactivity in the forebrain of 5-month-old L1fy + mice. Immunohistochemical analysis of $L 1$ expression in the brains of a 5 -month-old $L 1 f y$-mouse $(A$, $C, E, G)$ and $L 1 f y+$ littermate $(B, D, F, H)$. Coronal sections were immunostained with L1 polyclonal antibody. L1 immunoreactivity is markedly diminished in the cerebral cortex and hippocampus and thalamus $(B)$, striatum $(D)$, and hypothalamus $(F)$ of $L 1 f y+$ mice as compared with $L 7 f y$ - littermates $(A, C$, and $E$, respectively). L1 immunoreactivity was unchanged in the molecular layer of the cerebellum of $L 1 f y+$ mice $(H)$ as compared with $L 1 f y$ - mice $(G)$. Scale bar: (in H) A-H, 1 mm. 3v, Third ventricle; c, cortex; cc, corpus callosum; ds, dorsal striatum; f, fimbria; h, hippocampus; ht, hypothalamus; Iv, lateral ventricle; mt, mammillothalamic tract; $\mathrm{ml}$, molecular layer; ot, optic tract; $\mathrm{t}$, thalamus.

that of L1fy- littermates. The overall size and cytoarchitecture of the hippocampus of adult $L 1 f y+$ mice did not differ from those of L1fy- mice, as revealed by Nissl staining (Fig. $5 A, E$ ). Neurofilament immunostaining of adult L1fy+ and L1fy-brain sections showed no apparent differences in the structure and density of neuropil between the two genotypes (Fig. $5 B, F$ ). The number and morphology of parvalbumin-immunoreactive interneurons in the hippocampus of $L 1 f y+$ mice were also normal (Fig. $5 C, G$ ). No alteration in the intensity and pattern of glial fibrillary acidic protein immunoreactivity was found in $L 1 f y+$ mice (Fig. $5 D, H$ ).

\section{Behavioral analysis}

Open field

L1fy + mice $(N=12)$ showed increased locomotion and reduced thigmotaxis in the open field as compared with L1fy-littermates
$(N=12)$, suggesting an elevated exploratory drive combined with decreased anxiety in L1fy + mice. To test possible differences between genotypes in short-term habituation, all parameters were analyzed for the three consecutive 5 min intervals. The twoway ANOVA showed an effect of the genotype on distance moved $\left(F_{(1,22)}=5.17 ; p<0.05\right)$, mean velocity $\left(F_{(1,22)}=5.16 ; p<0.05\right)$, time spent in the center $\left(F_{(1,22)}=6.37 ; p<0.05\right)$, and entries into the center $\left(F_{(1,22)}=6.64 ; p<0.05\right)$ (Fig. $6 A-D$, respectively). As a result of short-term habituation to the apparatus, both genotypes moved less as they stayed longer in the open field (as shown by the significant effect of the time on distance moved and on mean velocity; data not shown). A significant effect of the interaction between genotype and time $\left(F_{(2,44)}=3.45 ; p<0.05\right)$ was observed for mean distance to the wall, an index of thigmotaxis. Post hoc analyses showed that L1fy + mice stayed at a higher mean distance to wall as compared with $L 1 f y$ - littermates only in the third 5 min interval (Fig. 6E). The increased time spent in the center and the higher number of entries into the center observed in L1fy + mice could have been a secondary effect of the increased locomotion of these mice. We therefore analyzed the distance moved in the center as percentage of the total distance moved in the arena. Also in this case, $L 1 f y+$ mice showed higher values as compared with $L 1 f y$ - mice $\left(F_{(2,44)}=7.17 ; p<0.05\right)$ (Fig. $\left.6 F\right)$. To test whether the two genotypes had a different response to the novel environment, mice were observed for the first $5 \mathrm{~min}$ of the test. An increased amount of rearing off wall was shown by L1fy+ mice $(19.1 \pm 2.3)$ as compared with L1fy- littermates $(9.8 \pm 2.1)$ $(p<0.01)$, whereas no difference between genotypes was found for the other behavioral parameters analyzed (stretch attend posture, self grooming, and rearing on wall).

\section{Elevated plus-maze}

Although locomotor activity (as measured by the number of total transitions and the number of entries into the closed arms) did not differ between the two genotypes (Fig. 7A,B), L1fy+ mice $(N=12)$ differed from their L1fy-control littermates $(N=12)$ in several parameters showing lower anxiety. L1fy + mice entered the open arms with lower latencies (Fig. 7D) and more often (Fig. $7 E$ ) and spent more time on the open arms (Fig. 7F) when compared with L1fy- mice. Moreover, L1fy + mice did less risk assessment than L1fy-mice (Fig. 7C). We also calculated the percentage of mice that explored the entire open arms reaching with their head the edge of the open arm farthest away from the center: $90 \%$ (9 of 10) of $L 1 f y+$ mice that had entered the open arms reached at least once the extreme edges, whereas only 33.3\% (2 of 6) of L1fymice did (Fisher's exact; $p<0.05$ ).

\section{Water maze: experiment 1}

The protocol of experiment 1 was designed to test the mice under different conditions (cued platform and spatial learning and relearning). No difference was detected between the two genotypes during training with the cued platform and during training with the hidden platform (Fig. 8A). L1fy + mice $(N=12)$ and L1fylittermates $(N=12)$ swam normally and climbed successfully onto the platform. Performance in the cued platform task revealed no sensorimotor or motivational abnormalities. Mice of both genotypes quickly reached average escape latencies of $<10$ sec and a path length of $<2 \mathrm{~m}$, and there was no floater during the entire training period. There was no effect of either the genotype or the interaction between genotype and trial on escape latency, path length, mean velocity, and minimal distance to the wall, as analyzed for the cued platform and spatial learning and relearning. 

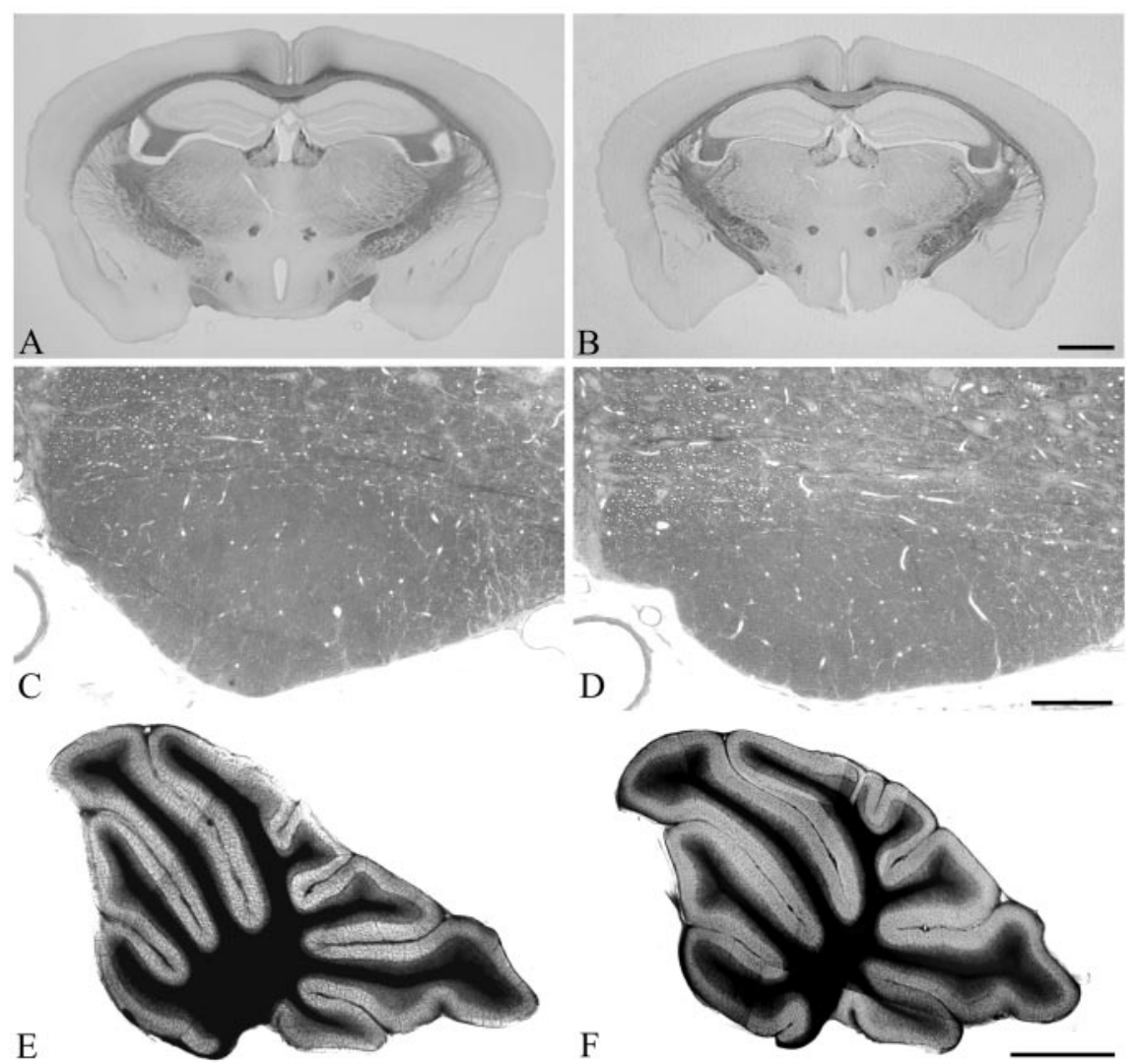

Figure 4. Light microscopy analysis of Nissl-stained sections of brains from 12-week-old mice. Coronal sections through the caudal region of the forebrain of an $L 17 y$ - mouse $(A)$ and an $L 1 f y+$ littermate $(B)$ show that the lateral ventricles in $L 1 f y+$ mice are of the same size as those of $L$ Ify- littermates. Scale bar: (in $B) A, B, 1 \mathrm{~mm}$. Cross sections through the corticospinal tract of an L1fy-mouse $(C$ and an $L 7 f y+$ littermate $(D)$ taken from corresponding levels of the medulla oblongata do not reveal differences between the two genotypes. Scale bar: (in D) C,D, $100 \mu \mathrm{m}$. Midsagittal sections through the cerebellum of an $L 1 f y$-mouse $(E)$ and an $L 1 f y+$ littermate $(F)$ show no signs of vermis hypoplasia in the $L 1 f y+$ mouse. Scale bar: (in $F) E, F, 1 \mathrm{~mm}$.
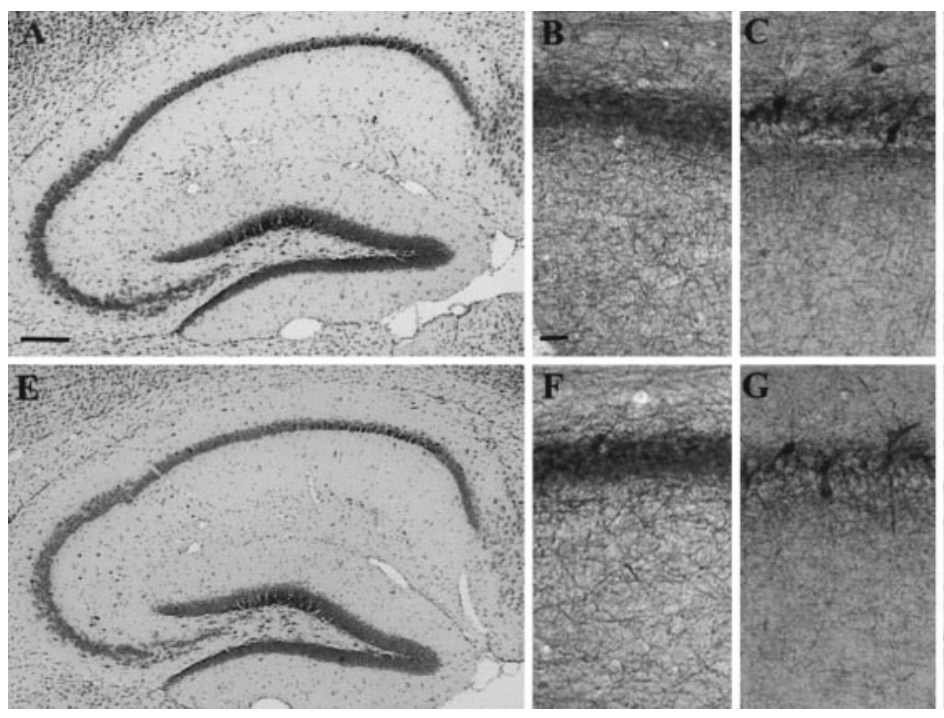

Figure 5. Histological and immunohistological analysis of hippocampi from 8-week-old mice. Niss-stained sagittal sections of the hippocampus from $L 17 y-(A)$ and $L 1 f y+(E)$ mice. Shown are immunostainings of sagittal sections of the CA1 subfield from $L 17 y$ - (top panel) and $L 1 f y+$ (bottom panels) mice for neurofilament $(B, F)$, parvalbumin $(C, G)$, and GFAP $(D, H)$. Scale bars: $A, 100 \mu \mathrm{m} ; B, 50 \mu \mathrm{m}$.

In the transfer trial performed after learning, L1fy- mice showed a preference for the target quadrant NE (percentage of time in quadrant NE: $39.5 \pm 5.4$ ), whereas $L 1 f y+$ littermates did not $(24.8 \pm 2.3)$, as shown by the significant effect of the interac-
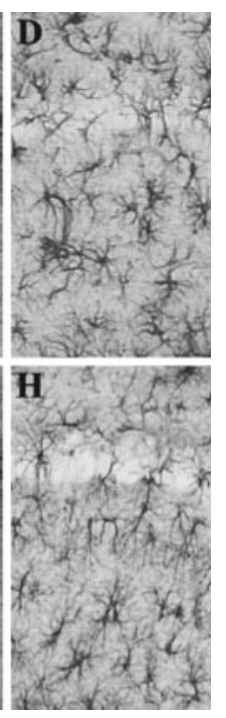

tion between genotype and quadrant $\left(F_{(3,66)}=4.48 ; p<0.01\right)$. Post hoc analyses revealed that $L 1 f y$ - mice spent more time in quadrant $\mathrm{NE}$ as compared with the time spent in the other three quadrants $(p<$ $0.05)$, as well as compared with the time spent in quadrant NE by Llfy + mice $(p<$ $0.01)$. In contrast, $L 1 f y+$ mice spent the same amount of time in the four quadrants. We performed a more detailed analysis of the search strategy used by the mice during the transfer trials by analyzing the time spent in an imaginary circular area (A) surrounding the ghost platform with a diameter of $28 \mathrm{~cm}$, twice the diameter of the platform. For control, time spent in three equivalent areas placed in the center of each of the other quadrants was analyzed. We also calculated the time spent by the mice in a ring including these areas, which corresponds to $35 \%$ of the total pool area (a scheme of the different areas and of the ring is shown in Fig. $8 B$ ). Both genotypes spent almost $70 \%$ of the total time swimming inside the ring, indicating that the mice searched at the appropriate distance from the wall to find the platform (Fig. 8C). There was no difference between genotypes either in the latency to enter the ghost platform or in the number of platform crossings. L1fy- mice, but not L1fy+ littermates, had a preference to swim in the target area northeast (ANE) during the transfer trial performed after learning (Fig. $8 D$ ). There was a significant effect of the interaction between genotype and area $\left(F_{(3,66)}=6.39 ; p<0.01\right)$. Post hoc analyses showed that L1fy- mice spent more time in the target area ANE as compared with the time spent in the other three control areas and as compared with Llfy + mice (Fig. $8 D$ ). It is possible that $L 1 f y+$ mice did not search in the target area during the transfer trial as a consequence of a relearning process after they did not find the platform. To test this hypothesis, we analyzed the time spent in the target area ANE in the three consecutive $20 \mathrm{sec}$ time intervals of the transfer trial (Fig. $8 E$ ). There was an effect of the genotype on time spent in ANE $\left(F_{(1,22)}=6.59 ; p<0.05\right)$. In addition, there was an effect of the interaction between genotype and time interval $\left(F_{(2,44)}\right.$ $=8.42 ; p=0.001)$. Post hoc analyses showed a difference between $L 1 f y+$ mice and L1fy- littermates in the first two 20 sec intervals, but not in the last one. In fact, during the transfer trial, $L 1 f y$ - mice decreased the time spent in the proximity of the platform reaching the values of Llfy + mice, which on the contrary did not change the time spent in the target area over the $60 \mathrm{sec}$ of the transfer trial (Fig. 8 E). Similar results were obtained when the time spent in the target area southeast 

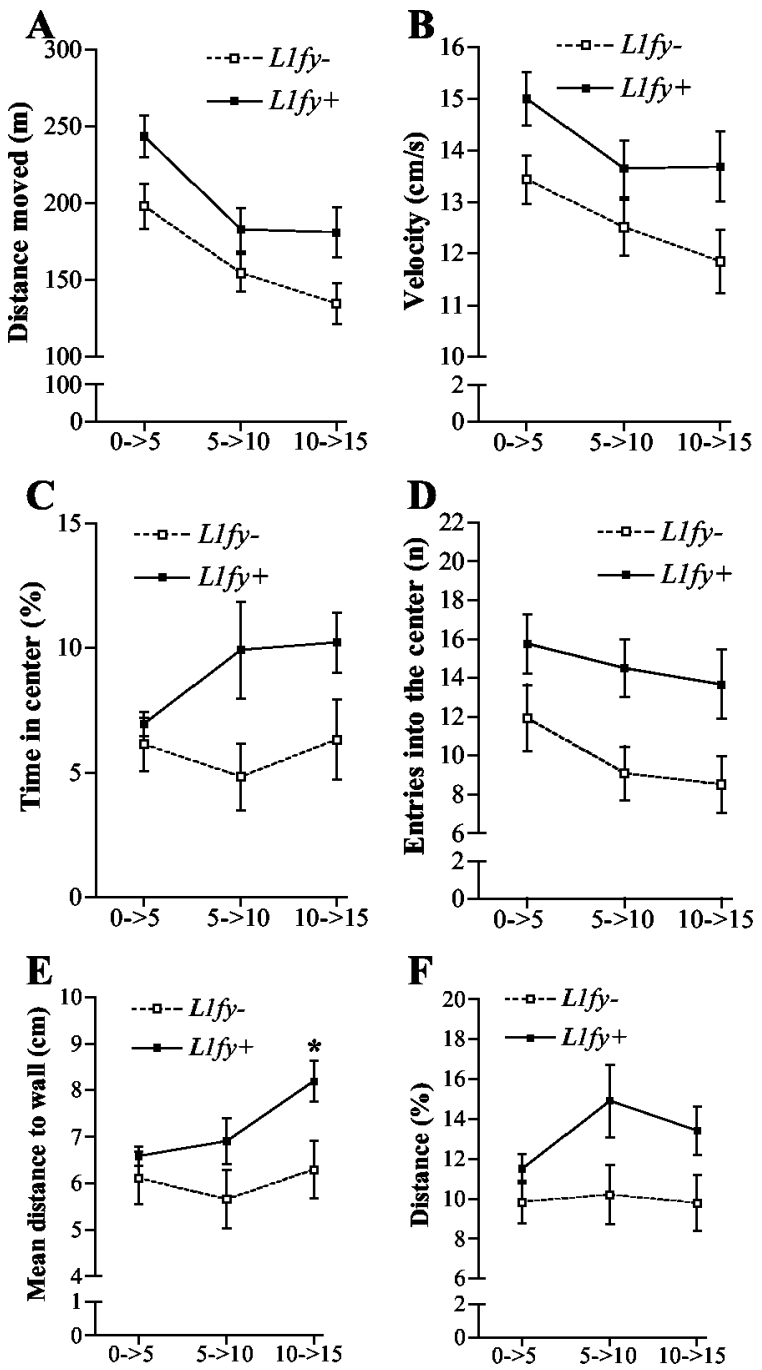

Time (min)
F

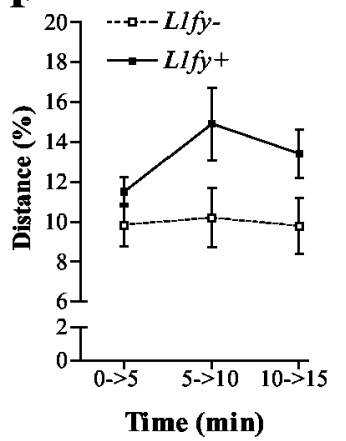

Figure 6. Increased locomotion and decreased anxiety toward the center of the open field in $L 1 f y+$ mice. $L 1 f y+$ mice moved more and entered more often into the central area of the open field as compared with $L 1 f y$ - littermates. The two-way ANOVA for repeated measures showed a significant effect of the genotype on distance (meters) moved $(A)$, mean velocity (centimeters per second) $(B)$, time (percentage) spent in the center $(C)$, number of entries into the center $(D)$, mean distance (centimeters) to wall $(E)$, and distance (percentage) moved in the center and total distance moved in the arena $(F)$ as calculated for the three consecutive 5 min intervals of the 15 min test. For mean distance to wall, there was also a significant effect of the interaction between genotype and time interval. Post hoc analyses revealed a significant difference between genotypes in the third 5 min interval. Each value represents the genotype mean \pm SEM. ${ }^{*} p<0.05$, as compared with L7fy- mice at the corresponding time interval (Newman-Keuls test after two-way ANOVA).

(ASE) was tested in the transfer trial performed after relearning (Fig. $8 F, G$ ).

We analyzed whether the two genotypes differed in other parameters during the transfer trials, such as path length, mean velocity, relative turning angle, relative turning velocity, absolute turning angle, and absolute turning velocity. No significant differences were detected, although during the first transfer trial, L1fy + mice tended to swim longer distances $(p=0.08)$ and with a higher mean velocity $(p=0.06)$ as compared with $L 1 f y$ - mice. When a $5 \mathrm{~cm}$ platform was used on day 11 , both genotypes required longer escape latencies (Fig. $8 \mathrm{~A}$ ). The similar escape latencies of the two genotypes did not support the hypothesis that a smaller platform would have given an advantage to the mice
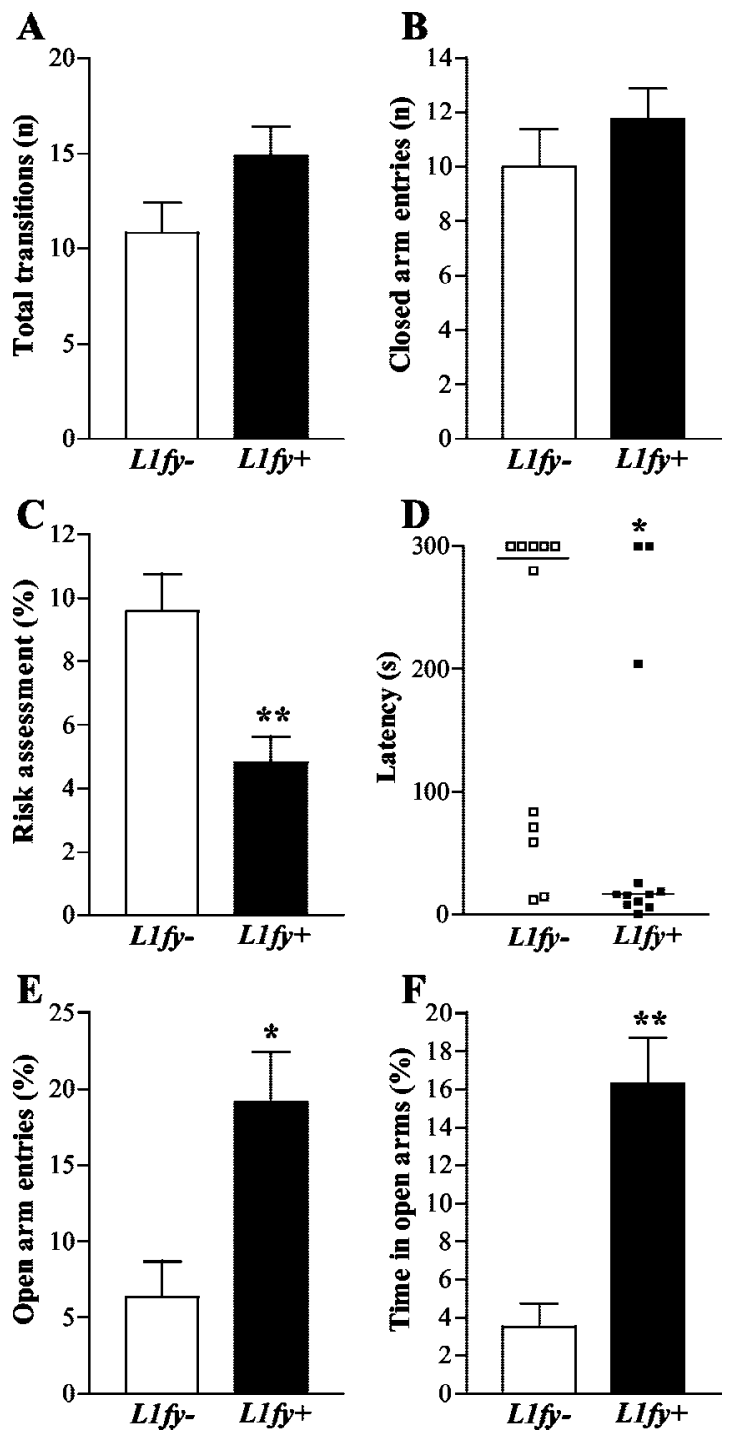

Figure 7. Decreased anxiety in L1fy + mice in the elevated plus-maze. $L 17 y+$ mice showed a higher propensity to explore the open arm of the elevated plus-maze as compared with their L1fy- littermates, whereas their general locomotor activity was unchanged. $A$, No difference in total transitions (entries into the open and closed arms) was detected between the two genotypes. $B$, Both genotypes showed $\sim 10$ entries into the closed arms. C, L1fy + mice spent less time (percentage), as compared with L1fy- littermates, in risk assessment toward the open arms while staying in the protected areas (closed arms and center). D, L1fy + mice entered the open arms with lower latencies as compared with $L 1 f y$-littermates. The latencies of each mouse are shown, and the median values are indicated with a line. $E, L 1 f y+$ mice entered more often the open arms (percentage of open arm entries and open and closed arms entries) as compared with L1fy- littermates. F, L1fy + mice spent more time (percentage) on the open arms as compared with $L 1 f y$ - littermates. Each value represents the genotype mean $\pm S E M$, except for $C$, where single data points are shown. ${ }^{*} p<0.05,{ }^{* *} p<0.01$, respectively, as compared with LIfy- mice (Mann-Whitney U test).

searching close to the platform. Nevertheless, the higher escape latencies obtained with the $5 \mathrm{~cm}$ platform allowed us to analyze the spatial preference of the mice during the first $25 \mathrm{sec}$ of three training trials. Statistical analysis confirmed the results from the transfer trials, showing that L1fy+ mice spent less time in the target area when compared with L1fy-control mice (effect of genotype: $\left.F_{(1,22)}=26.91 ; p<0.001\right)$.

Water maze: experiment 2

As in experiment 1, no difference was detected between genotypes during the cued platform task. Only 1 of 10 L1fy-mice and 

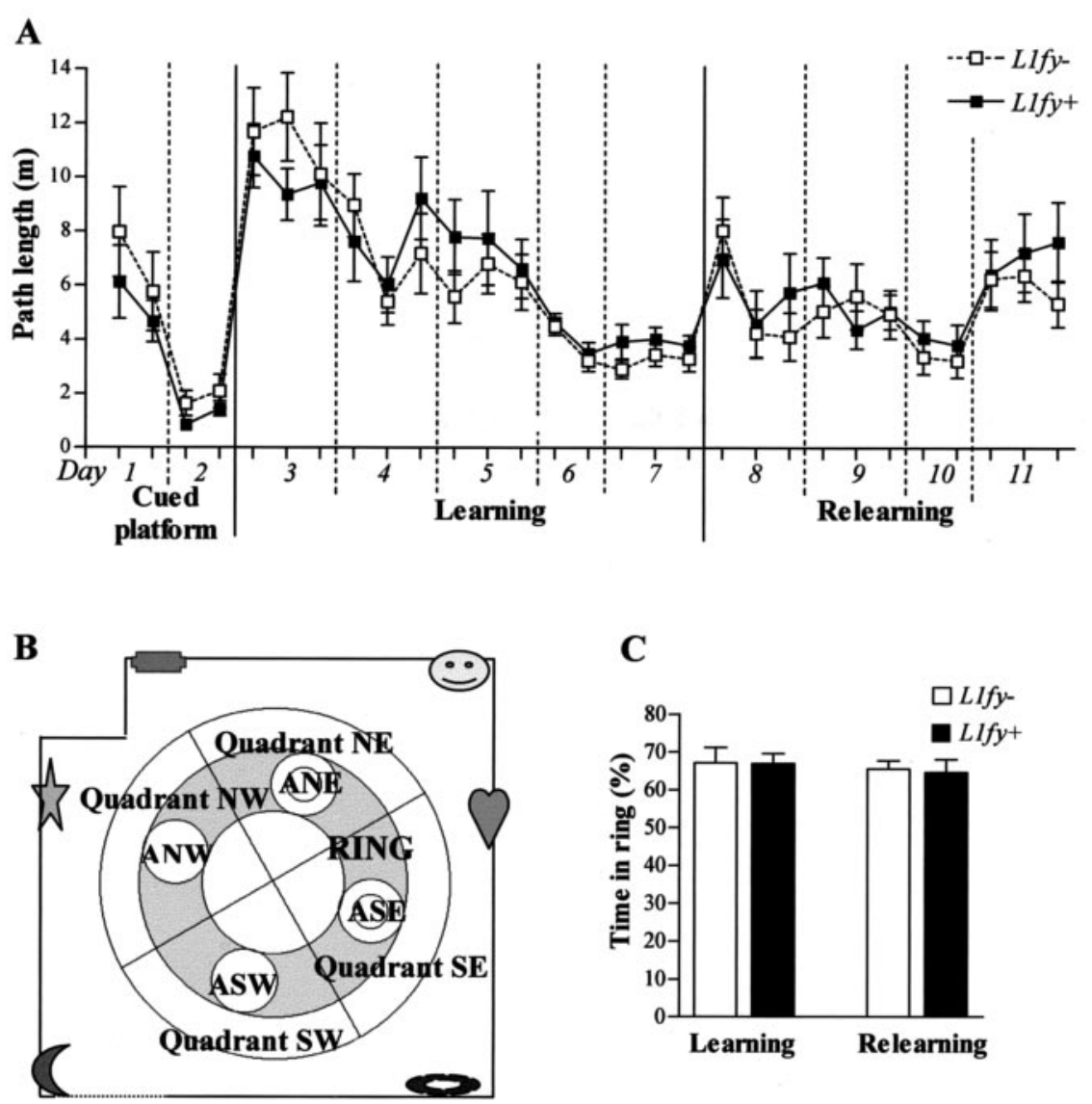

D
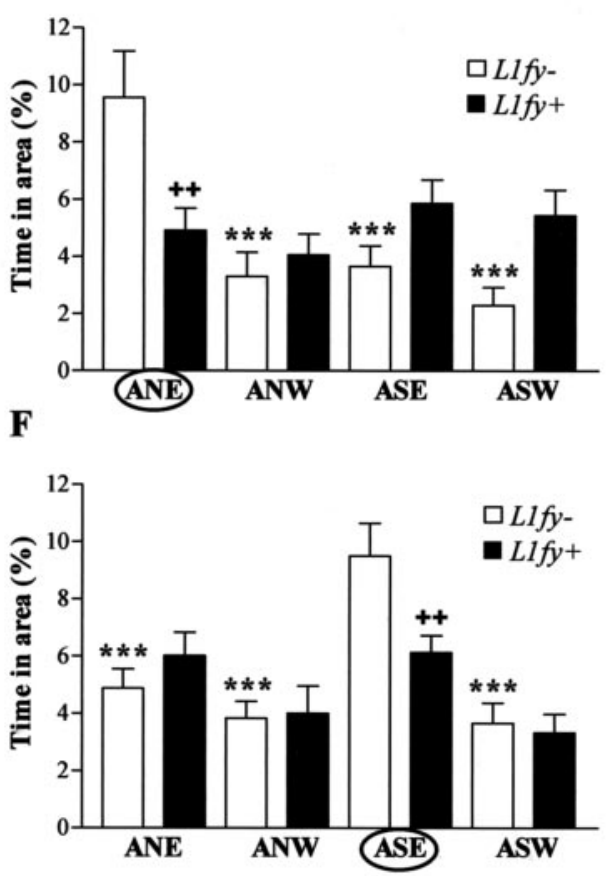

C

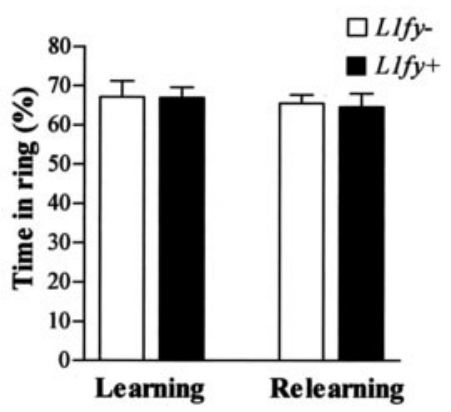

$\mathbf{E}$
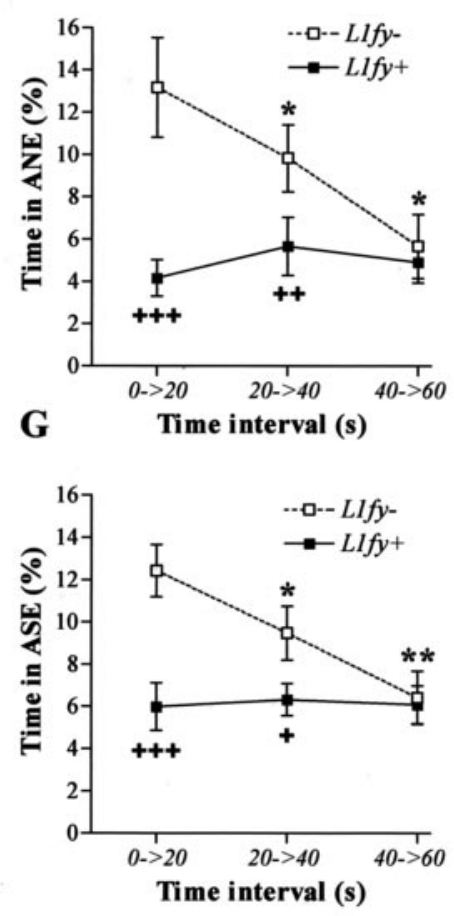

Figure 8. Altered search strategy in L1fy + mice in the water-maze experiment 1. A, Path length in the three different protocols: cued platform test, spatial learning, and spatial relearning. Each value represents the mean of two consecutive trials. No difference was detected between genotypes. $B$, Scheme of the experimental room. The dotted lines represent white curtains. Landmark positions at the walls are schematized. Two perpendicular lines divide the maze into four quadrants (NE, NW, SE, SW). ANE, ASE, ASW, and ANW are imaginary areas with a diameter of $28 \mathrm{~cm}$, twice the diameter of the platform. The platform was located in the center of areas ANE and ASE during learning and relearning, respectively. The gray sections plus the four areas represent the ring. $C$, Time spent in the ring during the transfer trials performed after learning and relearning. The ring represents

1 of 10 L1fy + mice performed badly with the cued platform as well as during the first 2 training days with the hidden platform, showing prolonged floating behavior. They were therefore excluded from subsequent training and analysis. Interestingly, the performance of both genotypes was better during the first $5 \mathrm{~d}$ of training with the hidden platform as compared with the performance during the corresponding training days of experiment 1 (three-way ANOVA having genotype and experiment as between factors and trials as within factors; effect of experiment: $F_{(1,40)}=4.83$; $p<0.04)$. There was no effect of either the genotype or of the interaction between genotype and trials on path length as analyzed for days 3-7 (when black stripes and landmarks were present) and days 10-11 (when landmarks were absent), whereas there was a significant effect of the interaction between genotype and trial $\left(F_{(5,80)}=\right.$ 5.83; $p<0.001)$ on path length on days 8-9 (when the black stripes were absent). Post hoc analysis showed that L1fy + mice swam significantly longer paths as compared with $L 1 f y$ - littermates in the first two trials on day $8(p<0.001)$ (Fig. 9A). We analyzed the percentage of time spent by the mice in area northwest (ANW), the area surrounding the platform position having a diameter of $28 \mathrm{~cm}$ (twice the diameter of the platform) (Fig. 9B) for all transfer trials (Fig. 9C). There was a significant effect of both the genotype $\left(F_{(1,16)}=\right.$ $14.99 ; p<0.01)$ and the interaction between genotype and day $\left(F_{(6,96)}=3.82\right.$; $p<0.01)$ on the percentage of time spent in ANW. Post hoc analyses showed that L1fy + mice spent less time in ANW as compared with L1fy- littermates only at day 6 , when the black stripes were absent $(p<0.01)$, and at day $17(p<0.001), 5 \mathrm{~d}$ after the last training (Fig. $9 C$ ).

Water maze: experiment 3

Mice were trained again 2 weeks after experiment 2 with two landmarks placed opposite each other on a circular curtain. On the first 2 training days (days 31-32) the platform was located in quadrant SE distant from both landmarks, whereas on the last 2 training days (days 33-34) the platform was placed in quadrant SW near one landmark (Fig. 9D). We analyzed path length with three-way ANOVA having genotype as between factor and platform position and trial as within factors, yielding a significant effect of the interaction between genotype and platform position $\left(F_{(1,16)}=12.56 ; p<0.01\right)$. Post hoc analyses showed that $L 1 f y+$ mice needed longer paths to reach the platform as compared 
with L1fy-mice when the platform was in SE $(p<0.001)$ but not when the platform was in SW. Moreover, L1fy + mice needed shorter path lengths to reach the platform when it was located in SW as compared with when the platform was in SE $(p=0.001)$. Analysis of the two transfer trials revealed that L1fy + mice spent less time in the target areas in both transfer trials as compared with L1fy- littermates (Fig. 9E).

\section{Electrophysiological analysis}

Because LTP in the CA1 region of the hippocampus has been implicated in spatial learning in laboratory rodents (Bliss and Collingridge, 1993), we asked whether L1fy + mice are compromised in this aspect. Although $L 1-/-$ mutants are not obviously impaired in hippocampal LTP (Bliss et al., 2000), this could be caused by developmental compensation of L1 functions by related molecules. TBS of Schaffer collaterals resulted in similar levels of potentiated fEPSPs recorded in the stratum radiatum of the CA1 region in L1fy + mice and L1fy- littermates. The mean slopes of fEPSPs recorded 50-60 min after TBS were $113.7 \pm$ $3.5 \%$ (number of mice, $N=5$; number of slices, $n=8$ ) in $L 1 f y+$ mice and $118.5 \pm 2.8 \%(N=5 ; n=9)$ in L1fy-mice $(p>0.05)$. The slope of fEPSPs evoked by stimulation of the control pathway did not show any significant long-lasting changes, confirming input specificity of the induced LTP (Fig. 10A,B). Potentiation immediately after TBS (measured as the maximal slope of fEPSPs within the first minutes after TBS) (Fig. 7A) and another form of short-term plasticity, paired-pulse facilitation of fEPSPs evoked by stimulation of Schaffer collaterals with interpulse intervals between 20 and $200 \mathrm{msec}$ (Fig. 10 D), were also indistinguishable between L1fy + mice and L1fy- littermates.

Analysis of stimulus-response curves in L1fy + mice and L1fylittermates revealed a significant increase in basal synaptic activity in the CA1 region of $L 1 f y+$ mice. The stimulus strengthfEPSP slope curve was steeper in L1fy + mice than in L1fy- mice (Fig. 10C), indicating larger evoked potentials in L1fy + mice than in L1fy- mice, when identical stimuli were applied. There was no difference between genotypes in the amplitude of prespike-presynaptic fiber volley (a measure of the number of stimulated axons) at all tested stimulation strengths (Fig. 10C), indicating normal levels of excitability of Schaffer collaterals/ commissural fibers. A difference in the stimulus strength-fEPSP slope curve could be caused by a lower level of synaptic inhibition in L1fy + mice. To test this possibility, activity-dependent disinhibition of excitatory synaptic transmission was analyzed (Thompson and Gähwiler, 1989) by measuring the potential of hippocampal slices to develop burst discharges in the form of multiple population spikes (polyspikes) in response to repetitive supramaximal stimulations. Stimulation of the Schaffer collateral/ commissural fiber pathway at $1 \mathrm{~Hz}$ for $20 \mathrm{sec}$ did not result in higher

\footnotetext{
$\leftarrow$

$35 \%$ of the total surface of the maze. Both genotypes showed a high preference to swim within the ring. D, F, Ability to search in the proximity of the platform was tested by calculating the time (percentage) spent in the area surrounding the former platform (ANE and ASE for learning and relearning, respectively).D, L1fy- mice, but not L Ify + littermates, showed a significant preference for the target area ANE during the transfer trial performed after learning. F, LIfy- mice, but not LIfy + mice, showed a significant preference for the target area ASE during the transfer trial performed after relearning. $E$, $G$, Time (percentage) spent in the target area at three 20 sec time intervals of the 60 sec transfer trials performed after learning and relearning, respectively. L1fy-mice, but not $L 7 f y+$ mice, showed a preference for the target area ANE during the first 40 sec of the transfer trial performed after learning $(E)$ and relearning $(G)$. Each value represents the genotype mean \pm SEM. Significance was calculated with Newman-Keuls post hoc test after a significant effect of the interaction between genotype and the within group factor. ${ }^{*} p<0.05,{ }^{* *} p<0.01,{ }^{* * *} p<$ 0.001 , respectively, as compared with time spent in the target area within the same genotype $(D, F)$ or as compared with the time spent in the target area in the previous time interval within the same genotype $(E, G) .{ }^{+} p<0.05,{ }^{++} p<0.01,{ }^{++} p<0.001$, respectively, as compared with $L 1 f y$ - mice for the same area $(D, F)$ or for the same time interval $(E, G)$.
}

polyspiking activity of CA1 pyramidal neurons in L1fy + mice than in L1fy- littermates ( $N=4$ for each group; $n=18$ and 17, respectively; unpaired $t$ test; $p>0.05$ ) (Fig. 10E). Quantitative analysis of the polyspike area also did not reveal any significant

\section{Discussion}

L1-/ - mice bear severe morphological abnormalities that complicate the interpretation of the behavioral alterations observed in these mutants (Fransen et al., 1998). We generated a mouse $(L 1 f y+)$ in which the L1 gene is inactivated in forebrain and hippocampus after cessation of the major developmental events and is normal in its development and indistinguishable from - control littermates in the gross anatomy and histology of the brain. L1fy + mice are therefore a suitable model to study L1

\section{Increased basal synaptic activity in CA1 of L1fy + mice}

Bliss et al. (2000) described unaltered CA1 LTP in hippocampal slices from $L 1-/-$ mutants induced either by theta burst or by high-frequency stimulation. Concordantly, we did not find abnormalities in CA1 LTP induced by theta burst or pairing of ferent stimulation with depolarization of the postsynaptic cell $\mathrm{mV}$ in $\mathrm{L1}-/-$ mutants (A. Saghatelyan, A. Dityatev, M. and LTP in CA1 and dentate gyrus were normal in anesthetized L1-/- mutants (Bliss et al., 2000). Similarly, our recordings in of $L 1 f y+$ mice showed normal paired-pulse facilitation and ta burst-induced LTP. Analysis of polyspiking activity indiramidal cells are normal in L1fy + mice.

Increased basal excitatory activity in CA1 of L1fy + mice as compared with $L 1 f y$ - mice is thus the only detectable difference between the two genotypes. It has been reported that changes in basal activity do not necessarily lead to abnormalities in short- or long-term potentiation (Fitzjohn et al., 2001). The normal relationship between stimulation strength and amplitude of prespike-presynaptic fiber volley in L1fy + mice suggests that L1 defiency leads to an increased postsynaptic response generated excitability of Schaffer collaterals. Interestingly, basal excitatory activity was not elevated in $L 1-/-$ mutants (Bliss at al., 2000). hese observations suggest that the $\mathrm{L} 1$ deficit is functionally comsor in $L 1-/-$ mutants during ontogenetic developto hippocampal slices of wild-type animals did not affect basal synaptic transmission, although it reduced CA1 LTP (Lüthi et al., ). It is thus possible that L1 antibodies interfere in yet unknown ways with L1-dependent intracellular signaling mechanisms, including acute changes in intracellular calcium (Schuch et al., 1989; Walsh and Doherty, 1997; Schmid et al., 2000), which do not affect basal synaptic transmission but participate in LTP.

\section{Decreased anxiety in L1fy+ mice}

In the open field, $L 1 f y+$ mice moved more and entered more often into the center of the arena as compared with their L1fycontrol littermates. The higher propensity of L1fy + mice to explore the center of the open field was independent of the higher locomotor activity of $L 1 f y+$ mice, because 
A

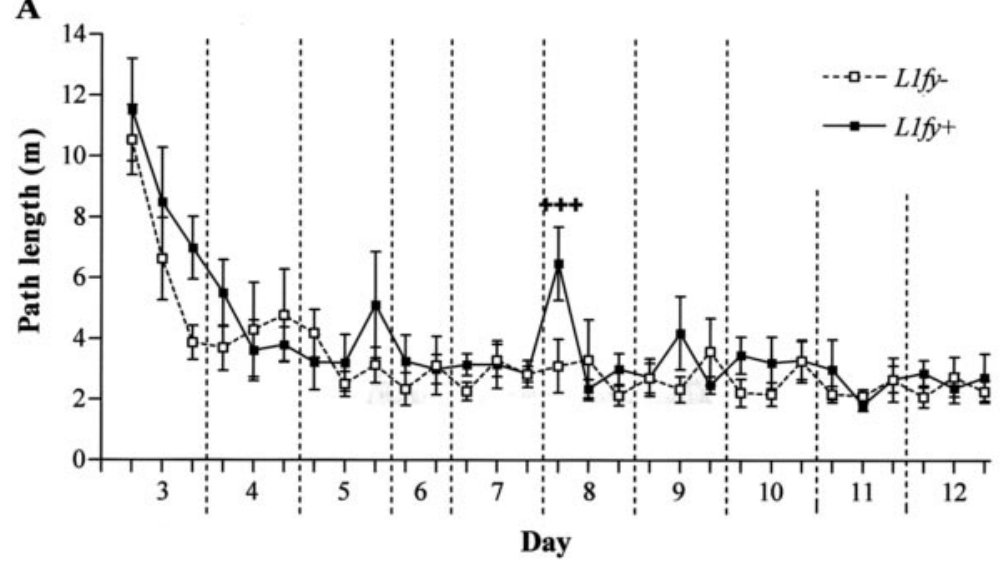

B

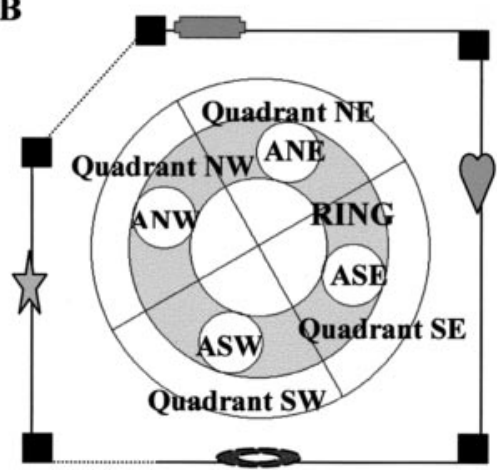

C
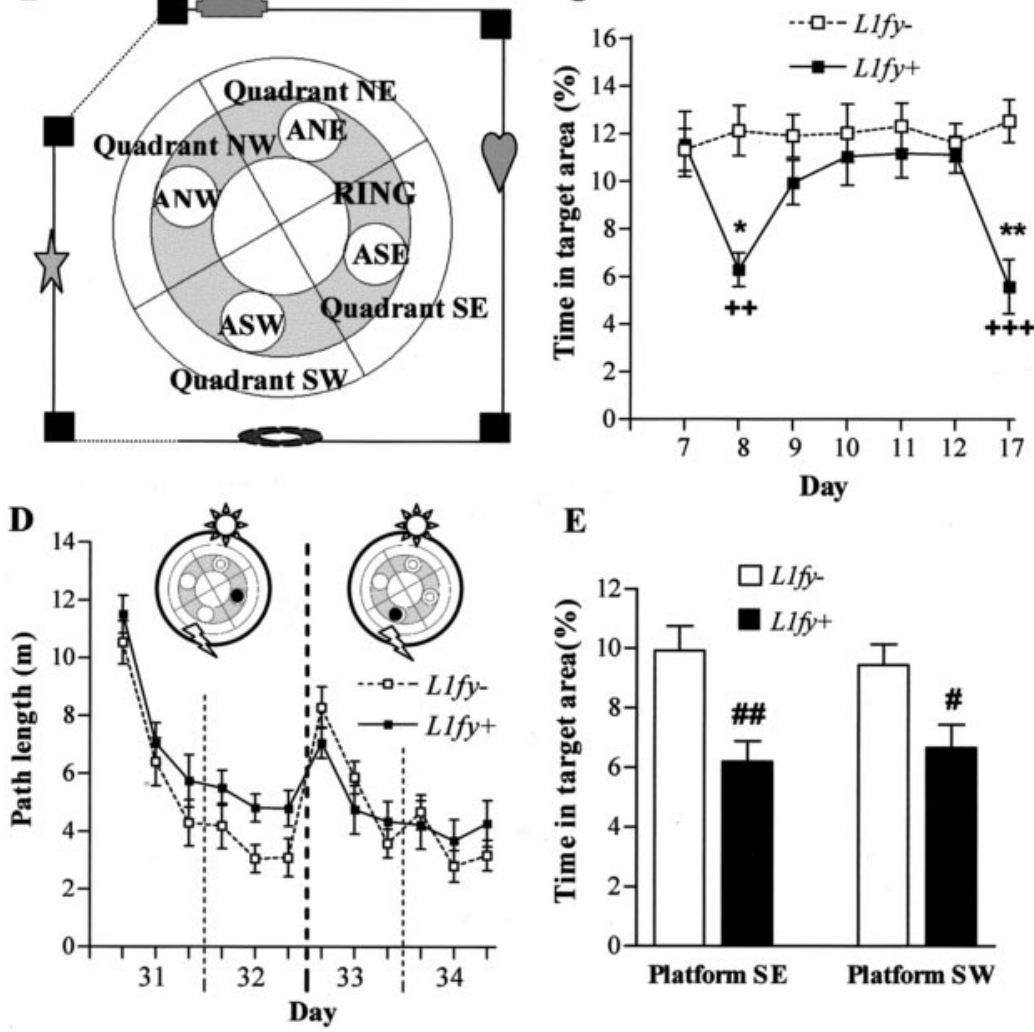

E

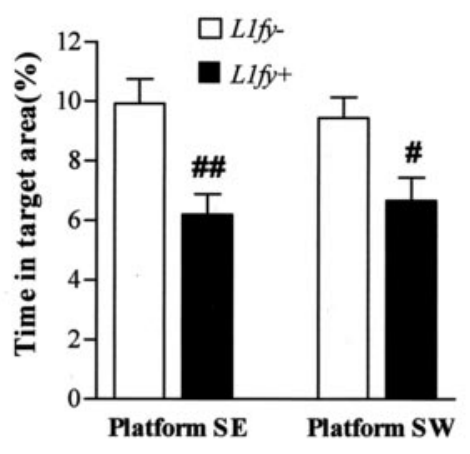

Figure 9. Altered use of visuospatial information in $L 1 f y+$ mice in the water-maze experiments 2 and 3. $A-C$, Results from experiment 2. $A$, Path length during acquisition in the hidden platform test. On days 8 and 9 the black stripes were absent, whereas on days 10-11 they were present and the landmarks were absent. For all the other days the room was as shown in $B$. Each value represents the mean of two consecutive trials. L1fy + mice needed longer paths to find the platform as compared with $L 1 f y$ littermates in the first two trials of day 8 , immediately after the stripes were removed from the corners. $B$, Schematic representation of the experimental room. The gray sections plus the four areas represent the ring. The dotted lines represent white curtains The positions of landmarks and black stripes at the walls and corners are schematized. Two perpendicular lines divide the pool into four quadrants (NE, NW, SE, SW). ANE, ASE, ASW, and ANW are the four areas with a diameter of $28 \mathrm{~cm}$, twice the diameter of the platform. The platform was located in the center of areas ANW.C, The ability to search the platform within a small area is tested for the seven transfer trials by calculating the time (percentage) spent in the target area surrounding the platform. Although L1fymice always had a preference for the target area, $L 1 f y+$ mice stayed less time in the target area on the transfer trials on day 8 (stripes absent) and on day 17 ( $5 \mathrm{~d}$ after the last training). D, E, Results from Experiment 3.D, Path length during acquisition of the hidden platform protocol during experiment 3 when two landmarks were located on a black circular curtain surrounding the pool. Each value represents the mean of two consecutive trials. On training days 31-32 the platform was located in SE and on days 33-34 it was in SW. L1fy + mice needed longer path lengths to find the platform on days 31 and 32 but not on days 33 and 34 , when the platform was near one of the landmarks. E, Time spent in the target area during the transfer trials performed at the end of training days 32 and 34. L1fy + mice spent less time as compared with L1fy- mice in the target area during both transfer trials. Each value represents the genotype mean \pm SEM. ${ }^{+} p<0.01$ and ${ }^{++} p<0.001$, respectively, as compared with $L 17 y$ - mice for the same trial or day; ${ }^{*} p<0.05$ and ${ }^{* *} p<0.01$, respectively, as compared with the previous day within the same genotype (Newman-Keuls post hoc test after a significant effect of the interaction between genotype and day). ${ }^{\#} p<0.05$ and ${ }^{\# \#} p<0.01$, respectively, as compared with $L 1 f y$ - mice (Mann-Whitney $U$ test).

distance moved in the center normalized by the total distance moved was also higher in L1fy + mice, and they made more rearing off wall, but not on wall, as compared with L1fy- mice. Similarly, L1fy+ mice were less anxious toward the open arms of the elevated plus-maze, whereas locomotor activity and exploration of the closed arms, as indicated by rearing behavior, was unaltered. These results point to a decreased state of anxiety in L1fy + mice, a considerably different phenotype as that described for $L 1-/-$ mutants (hypoactivity and stereotyped peripheral circling) (Fransen et al., 1998), supporting the idea that the behavioral alterations of $L 1-/-$ mutants relate to developmental abnormalities and cerebellar dysfunction. Thus, observations on L1fy + mice highlight a more specific function of L1 in the adult forebrain.

Altered place learning in L1fy + mice Place learning is defined as the ability of an animal to reach a goal by using the relational properties of distal cues, and it has been suggested to involve the hippocampus (Hirsh, 1974; Rudy and Sutherland, 1989). In contrast to L1fy- mice, L1fy+ mice did not show a spatial preference for the target in water-maze experiment 1 , although they had similar learning and relearning curves as L1fy- littermates. Indeed, latency and path length measured during training are sometimes not sufficient to distinguish between animals that show an alternative search strategy as compared with animals that use place learning (Hodges, 1996). Rats and mice can successfully find the hidden platform by using strategies that do not require place learning and an intact hippocampus (Morris et al., 1990; Whishaw et al., 1995; Lipp and Wolfer, 1998; Whishaw, 1998; D’Hooge and De Deyn, 2001). L1fy + mice swam at a proper distance from the wall, but they did not search in the proximity of the platform. Experiment 1 therefore indicates that $L 1 f y+$ mice find the platform as well as L1fy-mice do but use search strategies different from place learning. For instance, they could use a dominant cue in the room on which to base their response or simply acquire a set of response habits that guide them to the platform. It is noteworthy that the platform was not counterbalanced, a protocol that would have minimized possible biases toward one cue or one side of the pool. Nevertheless, the same data were obtained with the platform placed in quadrants NE and SE, indicating that the impairment of $L 1 f y+$ mice was robust, regardless of the platform position. 
Experiment 2 was performed in an experimental room with a strengthened asymmetric shape; mice could therefore locate the hidden platform also by using information about the geometry of the room (Cheng, 1986; Ramos, 2000). Indeed, both genotypes performed better during training with the hidden platform in experiment 2 as compared with mice tested in experiment 1. Moreover, L1fy+ mice preferentially searched in the target area during the transfer trials performed when the black stripes were present at the corners, suggesting that L1fy+ may require information about the shape of the environment for precise place location. Immediately after the black stripes were removed, L1fy + mice performed badly, and although they improved over the next trials, they did not show a preference for the target area during the transfer trial. Thus it is possible that L1fy + mice are not able to use the relational properties of different landmarks when no information about the geometry of the environment is available, thus switching to search strategies such as heading vectors (Pearce et al., 1998) and looping (Whishaw et al., 1995).

If $L 1 f y+$ mice find the hidden platform by heading vectors or looping, then their performance should depend strictly on the distance and position of the landmarks relative to the platform. In experiment 3, only two landmarks opposite to each other were placed on a circular curtain. As in experiment 1, L1fy + mice never showed spatial selectivity during both transfer trials. Moreover, L1fy + mice found the platform as well as L1fy-littermates when the platform was located near one landmark (days 33-34) but not when placed distant from both landmarks (days 31-32). Possibly, L1fy + mice were impaired in the first $2 \mathrm{~d}$ and then improved their performance in the last $2 \mathrm{~d}$ because they got used to the new environment and not as a consequence of the different platform position. L1fy + mice, however, never performed differently as compared with L1fy- mice during all the acquisition phases in experiments 1 and 2, during either learning or relearning. It is therefore likely that $L 1 f y+$ mice perform better when the platform is in the proximity of a landmark, a condition that can facilitate the use of vector or looping strategies, whereas such strategies are less effective when the platform is distant form the landmarks.

Finally, although $L 1 f y+$ mice selectively searched near the target during the last training day of experiment 2, they did not show any spatial selectivity in the transfer trial performed on day 17 with
$\mathbf{A}$

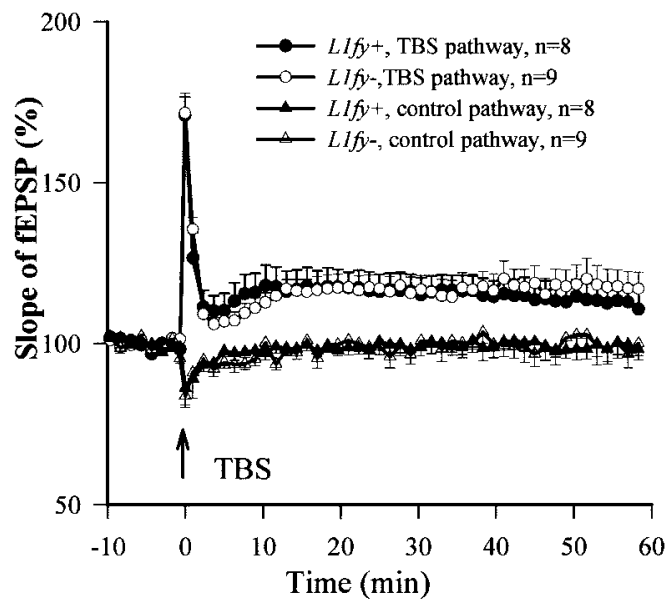

B

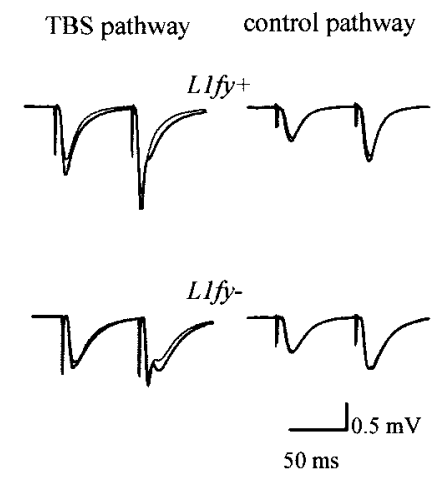

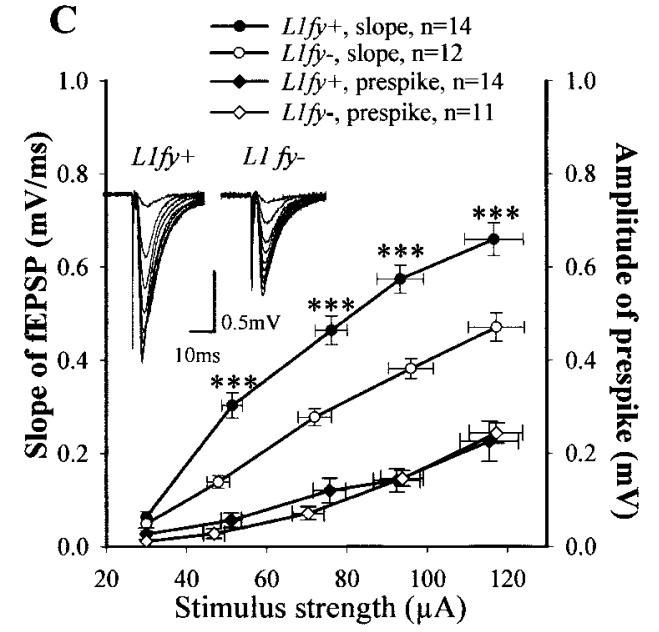

$\mathbf{E}$

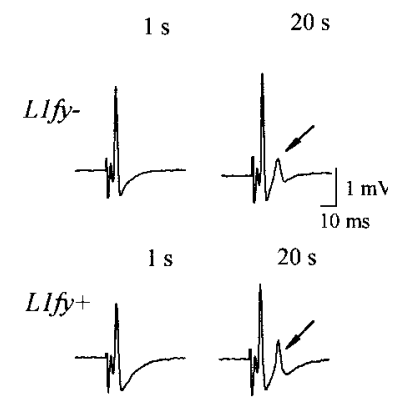

D

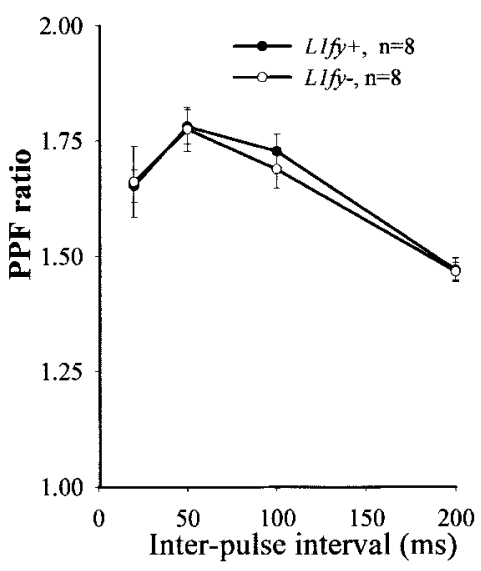

$\mathbf{F}$

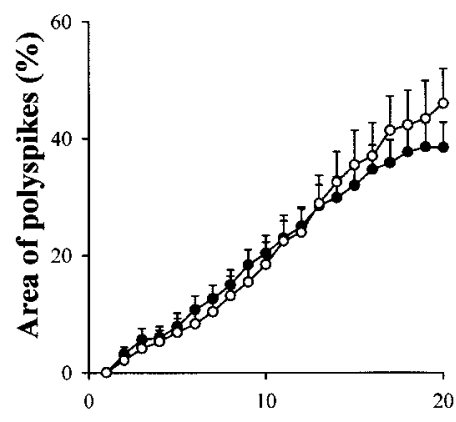

Figure 10. Normal LTP and multiple population spikes but elevated basal synaptic activity in L1fy + mice. A, LTP recorded in the CA1 subfield of hippocampal slices of $L 1 f y+$ and $L 1 f y$ - mice ( $8-10$ weeks old). TBS (indicated by arrow) of Schaffer collaterals evoked the same increase in the slopes of fEPSPs recorded in CA1 of slices from L1fy + mice $(-)$ as compared with L1fy- (O) littermates. Mean slope of fEPSPs recorded 0 -10 min before TBS was taken as $100 \%$. B, Averaged fEPSPs evoked by paired-pulse stimulation (interstimulus interval of $50 \mathrm{msec}$ ) recorded before and $60 \mathrm{~min}$ after TBS. C, Relationships between the stimulus strength and slope of fEPSP or amplitude of prespike-presynaptic fiber volley for $L 1 f y+$ and $L 17 y$ - mice. Data were expressed as mean \pm SEM. Traces of fEPSPs evoked with different stimulus strengths (by steps of $10 \mu \mathrm{A}$ ) are shown in the insets. D, Pairedpulse facilitation (PPF) was measured as the ratio between the slopes of fEPSPs evoked by the second and first pulses and plotted for several interpulse intervals. Field EPSPs were evoked with a stimulus being $30 \%$ of the maximal subthreshold strength. Values represent mean \pm SEM; $n=$ number of tested slices prepared from five LIfy + and five L1fy- mice. ${ }^{* * *} p<0.001$ (unpaired $t$ test). $E$, Examples of population spikes evoked by stimulation of Schaffer collaterals and recorded in the stratum pyramidale of CA1. After repetitive stimulation ( $1 \mathrm{~Hz}$ for $20 \mathrm{sec}$ ), slices from $L 17 y+$ mice exhibit polyspikes (multiple population spikes, arrow) at similar levels as L1fy- littermates. $F$, Time course of polyspike elevation during repetitive stimulation. The plot shows the area of the secondary spikes expressed as percentage of the area of the first population spike in slices from four $L 1 f y+(-)$ and four $L 1 f y-$ (○) mice. $n=$ number of hippocampal slices measured. 
Table 1. Phenotype of constitutively and conditionally L1-deficient mice

\begin{tabular}{|c|c|c|}
\hline & Constitutive L1 mutant (L1-/-) & Conditional L1 mutant $(L 1 f y+)$ \\
\hline & \multicolumn{2}{|l|}{ Smaller body size, less viable, hindlimb weakness, smaller and sunken } \\
\hline General appearance & eyes ${ }^{a, b}$ & Unaltered \\
\hline Ventricular dilatation & Degree of ventriculomegaly depends on strain background ${ }^{a}$ & Absent \\
\hline Corticospinal tract & Hypoplasia and impaired desussation $n^{b, c}$ & Unaltered \\
\hline Cerebellar vermis & Hypoplastic ${ }^{c}$ & Unaltered \\
\hline Granulosa layer of cerebellum & Unaltered ${ }^{c}$ & Unaltered \\
\hline Paired-pulse facilitation in CA1 & Unaltered $^{c}$ & Unaltered \\
\hline Thetaburst-induced LTP in CA1 & Unaltered $^{d}$ & Unaltered \\
\hline Basal excitatory activity in CA1 & Unaltered $^{d}$ & Increased \\
\hline Cage behavior & Hypoactivity ${ }^{c}$ & Not analyzed \\
\hline Open field & Stereotype periferal circling ${ }^{c}$ & Increased locomotion and exploration of the center \\
\hline Elevated-plus maze & Not analyzed & Increased exploration of the open arms \\
\hline Water maze & $\begin{array}{l}\text { Slower learning curve (attributable to decreased swimming velocity?) } \\
\text { and reduced spatial selectivity during transfer trial }\end{array}$ & Altered searching strategy and use of visible cues \\
\hline
\end{tabular}

${ }^{a}$ Dahme et al., 1997.

${ }^{b}$ Cohen et al., 1998.

'Fransen et al., 1997

${ }^{d}$ Bliss et al., 2000.

the same environmental setting. Because L1fy + mice already use different search strategies as compared with L1fy- mice during the acquisition phase of the water maze, it is not possible to make unequivocal conclusions regarding long-term memory function of these mice, at least as tested in this paradigm. It is tempting to speculate, however, that once L1fy + mice learn to use a cognitive map to localize the platform, they are not able to do so after a long time interval, a hypothesis that would be consistent with observations in zebrafish (Pradel et al., 2000) and chicks (Scholey et al., 1995; Tiunova et al., 1998), showing an involvement of L1 in long-term memory.

Similar to L1fy + mice, rats with continuous intraventricular infusion of polyclonal L1 antibodies into the hippocampus learned normally during the acquisition phase in the water maze but had an impaired spatial selectivity during the transfer trial (Arami et al., 1996). Similarly, L1-/- mice were less efficient in spatial selectivity than wild-type littermates (Fransen et al., 1998). Interestingly, ectopic expression of L1 in astrocytes led to higher spatial selectivity in transgenic mice tested in the water maze (Wolfer et al., 1998). The combined observations point to a concordance between different modes of altering L1 activity.

In conclusion, morphological, behavioral, and electrophysiological analyses of conditional L1-deficient mice allowed insights into the functional role of $\mathrm{L} 1$ in the adult mouse brain by permitting ontogenetic development to proceed normally in the presence of L1 (Table 1 shows a comparison between constitutive and conditional L1-deficient mice). Our electrophysiological data on basal synaptic transmission point to compensatory mechanisms in $L 1-/-$ mice that are not seen by inactivation of the L1 gene after cessation of development. The behavioral analyses indicate for the first time a role of L1 in the adult brain in regulating exploratory and anxiety-related behaviors. The alteration in place learning in L1fy + mice supports the hypothesis that L1 influences the molecular and cellular mechanisms underlying learning in the adult brain.

\section{References}

Arami S, Jucker M, Schachner M, Welzl H (1996) The effect of continuous intraventricular infusion of L1 and NCAM antibodies on spatial learning in rats. Behav Brain Res 81:81-87.

Benson DL, Schnapp LM, Shapiro L, Huntley GW (2000) Making memories stick: cell-adhesion molecules in synaptic plasticity. Trends Cell Biol 10:473-482.
Bliss TV, Collingridge GL (1993) A synaptic model of memory: long-term potentiation in the hippocampus. Nature 361:31-39.

Bliss TV, Errington M, Fransen E, Godfraind JM, Kauer JA, Kooy RF, Maness PF, Furley AJ (2000) Long-term potentiation in mice lacking the neural cell adhesion molecule L1. Curr Biol 10:1607-1610.

Chamizo VD (2002) Spatial learning: conditions and basic effects. Psicológica 23:35-57.

Cheng K (1986) A purely geometric module in the rat's spatial representation. Cognition 23:149-178.

Cohen NR, Taylor JS, Scott LB, Guillery RW, Soriano P, Furley AJ (1998) Errors in corticospinal axon guidance in mice lacking the neural cell adhesion molecule L1. Curr Biol 8:26-33.

Dahme M, Bartsch U, Martini R, Anliker B, Schachner M, Mantei N (1997) Disruption of the mouse L1 gene leads to malformations of the nervous system. Nat Genet 17:346-349.

D'Hooge R, De Deyn PP (2001) Applications of the Morris water maze in the study of learning and memory. Brain Res Brain Res Rev 36:60-90.

Dityatev A, Dityateva G, Schachner M (2000) Synaptic strength as a function of post- versus presynaptic expression of the neural cell adhesion molecule NCAM. Neuron 26:207-217.

Eckhardt M, Bukalo O, Chazal G, Wang L, Goridis C, Schachner M, GerardySchahn R, Cremer H, Dityatev A (2000) Mice deficient in the polysialyltransferase ST8SiaIV/PST-1 allow discrimination of the roles of neural cell adhesion molecule protein and polysialic acid in neural development and synaptic plasticity. J Neurosci 20:5234-5244.

Evers MR, Salmen B, Bukalo O, Rollenhagen A, Bosl MR, Morellini F, Bartsch U, Dityatev A, Schachner M (2002) Impairment of L-type $\mathrm{Ca}^{2+}$ channel-dependent forms of hippocampal synaptic plasticity in mice deficient in the extracellular matrix glycoprotein tenascin-C. J Neurosci 22:7177-7194.

Fannon AM, Colman DR (1996) A model for central synaptic junctional complex formation based on the differential adhesive specificities of the cadherins. Neuron 17:423-434.

Fischer G, Kunemund V, Schachner M (1986) Neurite outgrowth patterns in cerebellar microexplant cultures are affected by antibodies to the cell surface glycoprotein L1. J Neurosci 6:605-612.

Fitzjohn SM, Morton RA, Kuenzi F, Rosahl TW, Shearman M, Lewis H, Smith D, Reynolds DS, Davies CH, Collingridge GL, Seabrook GR (2001) Agerelated impairment of synaptic transmission but normal long-term potentiation in transgenic mice that overexpress the human APP695SWE mutant form of amyloid precursor protein. J Neurosci 21:4691-4698.

Franklin KBJ, Paxinos G (1997) The mouse brain in stereotaxic coordinates. San Diego: Academic.

Fransen E, D’Hooge R, Van Camp G, Verhoye M, Sijbers J, Reyniers E, Soriano P, Kamiguchi H, Willemsen R, Koekkoek SK, De Zeeuw CI, De Deyn PP, Van der LA, Lemmon V, Kooy RF, Willems PJ (1998) L1 knockout mice show dilated ventricles, vermis hypoplasia and impaired exploration patterns. Hum Mol Genet 7:999-1009. 
Gu H, Marth JD, Orban PC, Mossmann H, Rajewsky K (1994) Deletion of a DNA polymerase beta gene segment in T cells using cell type-specific gene targeting. Science 265:103-106.

Hirsh R (1974) The hippocampus and contextual retrieval of information from memory: a theory. Behav Biol 12:421-444.

Hodges H (1996) Maze procedure: the radial-arm and the water maze compared. Cognit Brain Res 3:167-181.

Kenwrick S, Watkins A, De Angelis E (2000) Neural cell recognition molecule L1: relating biological complexity to human disease mutations. Hum Mol 9:879-886.

Jacks T, Shih TS, Schmitt EM, Bronson RT, Bernards A, Weinberg RA (1994) Tumour predisposition in mice heterozygous for a targeted mutation in Nf1. Nat Genet 7:353-361.

Lindner J, Rathjen FG, Schachner M (1983) L1 mono- and polyclonal antibodies modify cell migration in early postnatal mouse cerebellum. Nature 305:427-430.

Lipp HP, Wolfer DP (1998) Genetically modified mice and cognition. Curr Opin Neurobiol 8:272-280.

Lüthi A, Laurent JP, Figurov A, Muller D, Schachner M (1994) Hippocampal long-term potentiation and neural cell adhesion molecules L1 and NCAM. Nature 372:777-779.

Lüthi A, Van der Putten H, Botteri FM, Mansuy IM, Meins M, Frey U, Sansig G, Portet C, Schmutz M, Schroder M, Nitsch C, Laurent JP, Monard D (1997) Endogenous serine protease inhibitor modulates epileptic activity and hippocampal long-term potentiation. J Neurosci 17:4688-4699.

Mantamadiotis T, Lemberger T, Bleckmann SC, Kern H, Kretz O, Martin Villalba A, Tronche F, Kellendonk C, Gau D, Kapfhammer J, Otto C, Schmid W, Schutz G (2002) Disruption of CREB function in brain leads to neurodegeneration. Nat Genet 31:47-54.

Mayford M, Wang J, Kandel ER, O’Dell TJ (1995) CaMKII regulates the frequency-response function of hippocampal synapses for the production of both LTD and LTP. Cell 81:891-904.

Minichiello L, Korte M, Wolfer D, Kuhn R, Unsicker K, Cestari V, RossiArnaud C, Lipp HP, Bonhoeffer T, Klein R (1999) Essential role for TrkB receptors in hippocampus-mediated learning. Neuron 24:401-414.

Morris RG, Schenk F, Tweedie F, Jarrard LE (1990) Ibotenate lesions of hippocampus and/or subiculum: dissociating components of allocentric spatial learning. Eur J Neurosci 2:1016-1028.

Muller D, Wang C, Skibo G, Toni N, Cremer H, Calaora V, Rougon G, Kiss JZ (1996) PSA-NCAM is required for activity-induced synaptic plasticity. Neuron 17:413-422.

Murase S, Schuman EM (1999) The role of cell adhesion molecules in synaptic plasticity and memory. Curr Opin Cell Biol 11:549-553.

O’Keefe J, Burgess N (1996) Geometric determinants of the place fields of hippocampal neurons. Nature 381:425-428.

Pearce J, Ward-Robinson J, Good M, Fussell C, Aydin A (2001) Influence of a beacon on spatial learning based on the shape pf the test environment. J Exp Psychol Anim Behav Process 27:329-344.

Pearce JM, Roberts AD, Good M (1998) Hippocampal lesions disrupt navigation based on cognitive maps but not heading vectors. Nature 96:75-77.

Perrin FE, Rathjen FG, Stoeckli ET (2001) Distinct subpopulations of sen- sory afferents require F11 or axonin-1 for growth to their target layers within the spinal cord of the chick. Neuron 30:707-723.

Pradel G, Schmidt R, Schachner M (2000) Involvement of L1.1 in memory consolidation after active avoidance conditioning in zebrafish. J Neurobiol 43:389-403.

Ramos JMJ (2000) Influence of the shape of the experimental room on spatial learning in rats. Physiol Behav 70:351-357.

Rathjen FG, Schachner M (1984) Immunocytological and biochemical characterization of a new neuronal cell surface component (L1 antigen) which is involved in cell adhesion. EMBO J 3:1-10.

Rudy JW, Sutherland RJ (1989) The hippocampal formation is necessary for rats to learn and remember configural discriminations. Behav Brain Res 34:97-109.

Saghatelyan AK, Gorissen S, Albert M, Hertlein B, Schachner M, Dityatev A (2000) The extracellular matrix molecule tenascin-R and its HNK-1 carbohydrate modulate perisomatic inhibition and long-term potentiation in the CA1 region of the hippocampus. Eur J Neurosci 12:3331-3342.

Schachner M (1997) Neural recognition molecules and synaptic plasticity. Curr Opin Cell Biol 9:627-634.

Schmid RS, Pruitt WM, Maness PF (2000) A MAP kinase-signaling pathway mediates neurite outgrowth on L1 and requires Src-dependent endocytosis. J Neurosci 20:4177-4188.

Scholey AB, Mileusnic R, Schachner M, Rose SP (1995) A role for a chicken homologue of the neural cell adhesion molecule L1 in consolidation of memory for a passive avoidance task in the chick. Learn Mem 2:17-25.

Schuch U, Lohse MJ, Schachner M (1989) Neural cell adhesion molecules influence second messenger systems. Neuron 3:13-20.

Staubli U, Chun D, Lynch G (1998) Time-dependent reversal of long-term potentiation by an integrin antagonist. J Neurosci 18:3460-3469.

Tang L, Hung CP, Schuman EM (1998) A role for the cadherin family of cell adhesion molecules in hippocampal long-term potentiation. Neuron 20:1165-1175.

Thompson SM, Gähwiler BH (1989) Activity-dependent disinhibition. I. Repetitive stimulation reduces IPSP driving force and conductance in the hippocampus in vitro. J Neurophysiol 61:501-511.

Tiunova A, Anokhin KV, Schachner M, Rose SP (1998) Three time windows for amnestic effect of antibodies to cell adhesion molecule L1 in chicks. NeuroReport 9:1645-1648.

Walsh FS, Doherty P (1997) Neural cell adhesion molecules of the immunoglobulin superfamily: role in axon growth and guidance. Annu Rev Cell Dev Biol 13:425-456.

Whishaw IQ (1998) Place learning in hippocampal rats and the path integration hypothesis. Neurosci Biobehav Rev 22:209-220.

Whishaw IQ, Cassel JC, Jarrad LE (1995) Rats with fimbria-fornix lesions display a place response in a swimming pool: a dissociation between getting there and knowing where. J Neurosci 15:5779-5788.

Wolfer DP, Mohajeri HM, Lipp HP, Schachner M (1998) Increased flexibility and selectivity in spatial learning of transgenic mice ectopically expressing the neural cell adhesion molecule L1 in astrocytes. Eur J Neurosci 10:708-717.

Wood PM, Schachner M, Bunge RP (1990) Inhibition of Schwann cell myelination in vitro by antibody to the L1 adhesion molecule. J Neurosci 10:3635-3645. 